\title{
Socio-economic productive capacities and energy efficiency: global evidence by income level and resource dependence
}

\author{
Mehmet Demiral $^{1}$ (D) Özge Demiral ${ }^{2}$ (D)
}

Received: 14 July 2021 / Accepted: 25 October 2021 / Published online: 8 November 2021

(c) The Author(s), under exclusive licence to Springer-Verlag GmbH Germany, part of Springer Nature 2021

\begin{abstract}
This study tests the effects of productive capacities in socio-economic factors (human capital, transport, information-communication technology, institutions, private sector, and structural change) on energy efficiency in a sample of 125 countries. Energy efficiency is assessed by energy productivity (gross domestic product per unit of total primary energy supply) and energy intensity (total primary energy supply per capita). The world sample is divided into four income groups and an income-heterogeneous control group of non-renewable-resource-dependent economies. The study utilizes cross-sectionally dependent and stationary panel data from 2000 to 2018. The analysis of variance shows that higher income groups monotonically have higher levels in socio-economic productive capacities and energy intensity. The regression results from appropriate fixed-effects and random-effects modeling reveal varied driver and barrier influences of the socio-economic factors on energy efficiency improvements (higher energy productivity and lower energy intensity). In some cases, predictors scale up both energy productivity and energy intensity indicating the issue of the rebound effect. Higher human capital capacity stimulates energy efficiency except for middle-income groups. Higher transport capacity reduces energy productivity, except for upper-middle-income economies, and increases energy intensity for low-income and middle-income groups. The deployment of information-communication technologies is positively associated with energy productivity, except for low-income economies. Energy productivity performance of resource-dependent economies is improved by higher productive capacities in institutions and private sectors but impaired by structural change, whereas structural change drives energy efficiency in low-income economies. Additionally, the growth of gross national income per capita worsens energy efficiency for resourcedependent economies. Bidirectional feedback causalities are established between energy efficiency and its predictors in most cases. The heterogeneous findings are further discussed for providing research and policy implications.
\end{abstract}

Keywords Energy efficiency $\cdot$ Energy productivity $\cdot$ Energy intensity $\cdot$ Productive capacity $\cdot$ Socio-economic factor . Income level $\cdot$ Resource dependence

\section{Introduction}

The economic growth of resource-scarce industrialized economies has been threatened by the increasing cost of energy shocks (Esseghir and Khouni 2014; Van de Ven and Fouquet 2017; Velasco-Fernández et al. 2020). Mean-

Responsible Editor: Eyup Dogan

Mehmet Demiral

mdemiral@ohu.edu.tr

Özge Demiral

odemiral@ohu.edu.tr

1 Department of Economics, Niğde Ömer Halisdemir University, 51240 Niğde, Turkey

2 Department of International Trade and Logistics, Niğde Ömer Halisdemir University, 51240 Niğde, Turkey while, some resource-abundant developing economies have been facing varied challenges of overdependence on the extraction of non-renewable energy resources (IMF 2012; Havranek et al. 2016; Zallé 2019). According to global trends in energy efficiency (OECD 2021) and economic growth (UNCTAD 2021a; World Bank 2021) data after the 1970s' oil crises, some industrialized countries seem to have been getting economic growth benefits from energy productivity improvements, while economic activities in 
many resource-abundant developing countries have been yet heavily relying on the extractive resources. Despite the well-evidenced fact that the depletion of energy resources has been exerting great pressure on the global economy, both production and consumption of the world have been increasingly demanding more energy. Rising demand has created new social and political challenges including energy insecurity and higher greenhouse gas emissions resulting from the increased consumption of fossil fuels. These challenges become more complicated given the preponderance of nonrenewable fossil sources (with a steady share of about $80 \%$ ) in the world energy production and the presence of an unacceptably high share of the world population without access to energy (OECD 2011; IEA 2019, 2020).

Global energy projections foresee neither a persistent decrease in the demand for energy nor a precise transition to renewable energy in the coming decades (IEA 2019, 2020). From the policy perspective on the world's energy future, the International Energy Agency's (IEA) current policies scenario reveals that energy demand rises by $1.3 \%$ each year from 2018 to 2040, if the world continues along with its present policies. In this prospective scenario, the energy demand will increase by about $34 \%$ from 14,314 million tons of oil equivalent in 2018 to 19,177 million tons of oil equivalent in 2040. This expected demand growth is followed by an about $24 \%$ increase in carbon dioxide $\left(\mathrm{CO}_{2}\right)$ emissions from 33.2 gigatons in 2018 to 41.3 gigatons in 2040 (IEA 2019). ${ }^{1}$

In line with the recognition of these stylized facts, many local and global energy policies have been prioritized to conserve energy resources, improve energy security, and mitigate environmental degradation. These global efforts can be broken down into two essential groups: A renewable energy transition from conventional fossil energy sources to low-carbon clean alternatives (solar, wind, biomass, hydropower, geothermal, and marine energies) (Ackah and Kizys 2015; Murshed 2020; Altinoz and Dogan 2021; Baloch et al. 2021; Nathaniel et al. 2021) and an overall improvement of energy efficiency (Sutherland 1994; Dunlop 2019; Goh and Ang 2020; Irfan 2021).

Energy efficiency, with its higher energy productivity and lower energy intensity meanings, is about less energy usage while both producing and consuming goods and services. Given the limited availability of non-renewable energy resources and the shortcoming of the current renewable energy supply, energy efficiency brings a variety of

\footnotetext{
1 The assessments of IEA (2020) show an about 5\% decline in global energy demand in 2020 , followed by $18 \%$ and $7 \%$ reductions, respectively in energy investment and energy-related $\mathrm{CO}_{2}$ emissions due to the economic downturn caused by the Covid-19 pandemic. However, since low economic growth is not an energy efficiency strategy, this study and its data exclude the temporary effects of the Covid-19 pandemic.
}

economywide and worldwide benefits. The ever-increasing need for responsible consumption and sustainable production of energy has forced policy-makers to formulate sound energy policies at both local and global levels. The energy efficiency initiatives, however, need more empirical evidence on the determinants of energy efficiency.

Using diverse concepts, an increasing number of studies from different fields have examined energy efficiency with a specific interest in the environmental degradation and carbonization side-effects of economic activities (Esseghir and Khouni 2014; Chang 2015; Atalla and Bean 2017; Dunlop 2019; He and Lin 2019; Azam et al. 2021). In addition, some non-economic determinants of energy efficiency have been recently explored for individual countries and/or different country groups. These determinants reflect the energy efficiency impacts of globalization, institutional quality, technological advancement and innovation, population dynamics and household demographics, urbanization, environmental agreements, energy policies, customer preferences, education, enterprise characteristics, and so on (Neumayer 2002; Cornillie and Fankhauser 2004; Hang and Tu 2007; Liddle 2014; Martinez 2016; Atalla and Bean 2017; Sineviciene et al. 2017; Nyangon and Byrne 2021). As many of these socio-technical determinants also have economic origins, there has emerged a relatively newer approach to energy efficiency from a socio-economic perspective especially in social sciences. However, not much research has adopted this perspective and relatively fewer studies have considered socio-economic determinants such as human capital (Blanco and Grier 2012; Zallé 2019; Nathaniel et al. 2021), transport and logistics performance (Figueroa et al. 2014; Liu et al. 2018; Li et al. 2021a, b), digital transformation and information-communication technology advancement (Sadorsky 2012; Schulte et al. 2016; Yan et al. 2018), institutional quality (Castiglione et al. 2015; Sun et al. 2019; Azam et al. 2021), private sector and business environment (Chang 2015; Martinez 2016; Rieger 2019), and structural change (Nepal et al. 2014; Atalla and Bean 2017; Sineviciene et al. 2017). Studies cover these variables separately and tend to suffer from the missed effects (omitted variables) as they do not capture the overall impacts of the interconnected socioeconomic factors.

Conventionally, energy efficiency is measured by either energy productivity (output per energy) or its inverse, i.e., energy intensity (energy per output) ${ }^{2}$ (Goldemberg 1996; UNIDO 2011; IEA 2019). Consistently, there is a tendency to consider only either energy productivity (Atalla and Bean 2017; Ryan 2018; Yan et al. 2018) or energy intensity

\footnotetext{
${ }^{2}$ In this study, the expression of energy efficiency refers to both (higher) energy productivity and (lower) energy intensity unless separately stated.
} 
(Cornillie and Fankhauser 2004; Chang 2015; Murshed $2020)$ relying on the reverse meaning. This approach, however, does not capture individual energy consumption and potential rebound (take-back) effects. The rebound effect indicates that more energy is consumed because of the financial gains enabled by the energy productivity increases (Galvin 2015; Adetutu et al. 2016; Nyangon and Byrne 2021); thus, energy consumption needs to be included in energy intensity measures. From the research perspective, the rebound effect occurs when one factor increases both energy productivity and consumption-led energy intensity. From the policy perspective, this means that the improvement of the overall energy efficiency will be more difficult than commonly assumed by the oversimplified approaches.

Global energy demand also depends upon the preferences of the population and the economic decisions of business organizations and individuals. Thus, energy efficiency measured by output per energy supply or its inverse ignores the consumption side of energy and fails to fully capture the overall energy efficiency performance of countries. The existing studies cover individual countries (Takase and Murota 2004; He and Lin 2019; Nyangon and Byrne 2021) or some groups of countries classified by region (Esseghir and Khouni 2014; Liu et al. 2018; Li et al. 2021a, b), income level/development stage (Chang 2015; Ozturk et al. 2019; Sun et al. 2019), or some economic blocs such as OECD (Salahuddin and Alam 2016; Schulte et al. 2016) and BRICS (Baloch et al. 2020; Nathaniel et al. 2021). These studies do not provide world evidence.

Overall, the review of extant literature about energy efficiency explains that the available empirical evidence contests and thus limits the preparation of policies. We believe that one reason for this is the less attention paid to socio-economic factors and the interchangeably use of the energy efficiency, energy productivity, and energy intensity concepts. By addressing the interdependence of energy efficiency and productive capacities, we suggest that productive capacities in socio-economic factors may be affecting the energy efficiency performance of countries depending on their income level and resource dependence. From the socio-economic and socio-technical perspectives, most of the previous cross-country studies miss the issue of the co-existence of unobservable latent effects of socio-economic factors. These effects can be captured through using multidimensionally constructed and internationally harmonized composite proxies which are limited by the lack of reliable and comparable measures. In this regard, the world-level availability of the Productive Capacities Index (PCI) metrics provided recently by the United Nations Conference on Trade and Development (UNCTAD) has filled an important gap.

Using PCI metrics, this study focuses on the examination of the impacts of productive capacities in socioeconomic factors including human capital, transport, information-communication technology (ICT), institutions, private sector, and structural change on energy efficiency for a world sample. Adopting a multi-perspective approach to energy efficiency and its potential socio-economic determinants, the study addresses five hypothesized questions: (i) Do country groups designated by income level and nonrenewable resource dependence have different levels in energy efficiency performances and socio-economic productive capacities? (ii) Do socio-economic productive capacities and per capita income differently affect energy efficiency performances of country groups? (iii) Do the impacts of socio-economic productive capacities and per capita income on energy efficiency change over the energy productivity and energy intensity measurements. (iv) Do socio-economic productive capacities and per capita income cause rebound effects by increasing both energy productivity and energy intensity? (v) Are there feedback loops within and between the socio-economic capacities and energy efficiency indicators?

To test these hypotheses, this study applies sequent analyses including analysis of variance, regression modeling, and causality analysis. The study uses a 19-year (2000-2018) panel dataset of 125 countries divided into four income groups (from low-income to high-income) and an incomeheterogeneous control group of non-renewable-resourcedependent economies. ${ }^{3}$ The study is able to distinctively contribute to the literature in mainly three respects. First, it considers both energy productivity (output per energy supply) and energy intensity (energy supply per capita) elements of energy efficiency. This combination introduces a new perspective of energy efficiency and enables us to check simultaneously how energy productivity gains may be lost by energy intensity rises, and vice versa. The exploration of these potential rebound effects as well as feedback causalities will also explain some of the ambiguity and controversiality of the existing evidence. Second, unlike most of the previous work, this study adopts a holistic approach and uses multidimensionally constructed composite indices of socio-economic factors. Thus, the study will provide results that are robust to omitted socio-economic variables. Third, the income designation captures how the income and development levels matter for the influences of socio-economic capacities on energy efficiency. The sub-sample of nonrenewable-resource-dependent countries will also help in extending the implications of the resource curse hypothesis to the energy efficiency context.

\footnotetext{
${ }^{3}$ Group characteristics such as income level, development stage, resource dependence, etc., may change over time for individual countries. In this study, the designations of countries by these common characteristics are intended for only statistical convenience without expressing any judgment.
} 
In the rest of the study, the next section describes the concepts of energy efficiency and socio-economic productive capacity followed by an outline of the reviewed literature. Then, the sample and data section introduces country sampling and data, represents summary statistics and correlations, and inspects the cross-sectional dependency and stationarity diagnostics. The hypotheses and analysis section explains research hypotheses and analytical framework. After the significant results are compared with the tested hypotheses and previous evidence, the study concludes with the highlights of the findings and their limitations to give some policy and research insights.

\section{Energy efficiency and productive capacity}

As a transdisciplinary and multidimensional concept, energy efficiency is defined differently by a wide range of scientific fields. There are also differences between academic and policy-oriented definitions. In all definitions, energy efficiency commonly means the use of less energy to produce the same or more quantity of output (Dunlop 2019; Goh and Ang 2020; Velasco-Fernández et al. 2020). Therefore, it is typically measured as output per energy (output/energy input) and used interchangeably with energy productivity, especially at the macro-level. The inverse, i.e., energy use per output (energy input/output), is also widely recognized as energy intensity (Cornillie and Fankhauser 2004; Takase and Murota 2004; Atalla and Bean 2017). In practice, either energy productivity or energy intensity is often taken as a proxy for energy efficiency (Cornillie and Fankhauser 2004; Steinberger and Krausmann 2011; Goh and Ang 2020). These output measures, however, are insufficient as they ignore the consumption side, which may take back the energy productivity gains by increasing energy intensity (Adetutu et al. 2016).

Unlike the one-indicator studies, we assess energy efficiency by considering energy productivity and energy intensity. From a production-side perspective and within an energy supply approach, energy productivity has been, as usual, proxied by gross domestic product (GDP) per unit of total primary energy supply (TPES). However, we have gauged energy intensity as TPES per capita, not per GDP, to control for the energy consumption patterns of societies, i.e., the ways people use energy to do things to meet their needs. TPES is defined as production and imports of energy, minus energy exports and international bunkers, plus or minus stock changes (OECD 2017; OECD 2021). This distinction helps in capturing the difference between the productive use of energy sources (increased energy productivity) and the use of fewer energy resources (declined energy intensity) (Sutherland 1994). According to these descriptions, a country may increase its overall energy productivity by either producing more at the same energy use or using less energy for the same production, or both. Energy intensity can be eased by reducing overall energy-related consumption or changing consumption behaviors towards more energyefficient products. Based on these conditions, our study combines higher energy productivity and lesser energy intensity with overall energy efficiency to better track the potential rebound effects.

Energy efficiency is driven and/or retarded by different factors including socio-economic capacities. Large-sample studies lack internationally comparable data of socio-economic capacities. However, recently, the UNCTAD (2021a, b) provides the Productive Capacities Index (PCI) relying on the premise that productive capacities are essential for generating inclusive economic growth and achieving sustainable development. As the leading initiative to measure productive capacities multidimensionally in all economies, the PCI measures enable policy-makers to formulate energy efficiency policies and benchmark their achievements. The PCI metrics vary between 1 (the lowest productive capacity) and 100 (the highest productive capacity). The PCI project currently covers 193 economies for the period 2000-2018 based on 46 indicators (UNCTAD 2021a). The overall PCI is divided into some categories, which, among others, are shown in Table 1.

\section{Relevant literature}

Many studies have contributed to the evaluation of energy efficiency performance using different indicators and analytical techniques within both the country-level and multicountry empirical settings. Income level has been one of the widely used predictors of energy efficiency but socio-economic factors have been relatively underrepresented. To the best of our knowledge, there is no study using the recently initiated PCI metrics to measure socio-economic capacities in the context of energy efficiency and its related concepts. Yet, a relevant body of the literature has been reviewed to highlight the potential contributions of this study.

(i) Income: The existing literature does not provide a consensus on the nexus amid income and energy efficiency as the relative importance of two contradictory influences tends to vary across countries: Higher per capita income, on the one hand, can provide possibilities for investing in energy-efficient new technologies while, on the other hand, it increases the energy demand. From the energy intensity and energy consumption perspectives, this argument is in line with the premised tradeoff effect between economic growth and environmental performance (Le and Ozturk 2020). An analysis by Chang (2015) on a sample of 53 countries for the 
Table 1 Selected categories of UNCTAD productive capacities

\begin{tabular}{|c|c|}
\hline Categories & Coverage \\
\hline $\begin{array}{l}\text { Human capital } \\
(P C I h c)\end{array}$ & $\begin{array}{l}\text { The education, skills, and health conditions of the population; research and development expenditures; the number of } \\
\text { researchers; and fertility (higher fertility rate reduces human capital score) }\end{array}$ \\
\hline $\begin{array}{l}\text { Transport } \\
(\text { PCItr })\end{array}$ & $\begin{array}{l}\text { The availability and quality of roads and railway networks and air connectivity to transport people or products between } \\
\text { destinations }\end{array}$ \\
\hline $\begin{array}{l}\text { ICT } \\
(\text { PCIitc })\end{array}$ & $\begin{array}{l}\text { The accessibility, integration, use, and security of communication systems and servers (fixed-line and mobile phones, and } \\
\text { internet accessibility) within the population }\end{array}$ \\
\hline $\begin{array}{l}\text { Institutions } \\
(\text { PCIins })\end{array}$ & $\begin{array}{l}\text { Political stability; regulatory quality; success in fighting criminality, corruption, and terrorism; and safeguard of citizens' } \\
\text { freedom of expression and association }\end{array}$ \\
\hline $\begin{array}{l}\text { Private sector } \\
(\text { PCIps })\end{array}$ & $\begin{array}{l}\text { The ease of international trade (time and monetary costs to export and import); the support to business in terms of domestic } \\
\text { credit; velocity of contract enforcement; and time required to start a business }\end{array}$ \\
\hline $\begin{array}{l}\text { Structural change } \\
(P C I s c)\end{array}$ & $\begin{array}{l}\text { The movement of resources from low to high productive economic activities both within and between sectors. This shift is } \\
\text { captured by the sophistication and diversification of exports, the intensity of fixed capital, and the shares of industry and } \\
\text { services in domestic production }\end{array}$ \\
\hline
\end{tabular}

Source: UNCTAD (2021a, b)

period 1999-2008 shows that energy consumption increases with the income growth in relatively lowerincome emerging and developing economies, while energy consumption pattern changes in high-income advanced economies depending on different levels of income. Atalla and Bean (2017) investigate the drivers of energy productivity (output per unit of energy use) changes in 39 countries during 1995-2009 and find that higher income is associated with greater energy productivity improvement. Sineviciene et al. (2017) identify GDP growth as a key factor increasing both energy efficiency and energy consumption for the panel of 11 post-communist countries in Eastern Europe during 1996-2013. Azam et al.'s (2021) results reveal that GDP growth increases energy consumption as well as environmental pollution for the 1991-2017 period of 66 developing countries.

As energy consumption is the main cause of global anthropogenic greenhouse gas emissions, both energy productivity (positively) and energy intensity (negatively) are also used to assess the environmental performance of countries (Alarenan et al. 2019; Baloch et al. 2020; Li et al. 2021a, b). The EKC hypothesis premises that when the level of economic development is high, people begin to pay more attention to environmental protection. Within the EKC framework, environmental degradation is sometimes measured by proxies of energy intensity. For example, based on the 2003-2017 data of China's provinces, He and Lin (2019) find that the income elasticity of emission pollution is positive (negative) when the energy intensity is higher (lower). Besides, as found by Esseghir and Khouni (2014) for 38 Union for the Mediterranean countries from 1980 to 2010, energy use and economic growth may also be related bidirectionally. Furthermore, energy consumption may cause income growth as discovered by Soytas and Sari (2003) in the cases of Turkey, France, Germany, and Japan.

Based on the optimistic view, the energy intensity falls if GDP continues to grow, but current global trends do not seem to be supporting this expectation. This unfavorable direction opens the doors to the debate on the rebound effects between income and energy intensity as these effects may cause underestimation of future energy demand (Brockway et al. 2021).

(ii) Human capital capacity: Although it is well known that resource distortions mainly emanate from human activities, studies on energy efficiency have little considered the impact of human development. The human capital level of societies is important not only for their consumption but also for their producers as companies have their owners and employees from the population. More specifically, well-educated people (consumers) know better how and why to save energy, which is important in especially resourcedependent countries. Zallé (2019) analyzes data of 29 countries from 2000 to 2015 and shows that investing in human capital helps in turning the curse of natural resources into a blessing. Meanwhile, resource dependence may also worsen human capital, albeit raising physical capital, as evidenced by Blanco and Grier (2012) for 17 Latin American countries during the 1975-2004 period. Based on the analysis covering the 1992-2016 period, Pata et al. (2021) verify that resource abundance damages the environment but human development lessens environmental pollution for 10 countries with a large ecological footprint. Nevertheless, Nathaniel et al. (2021) show that human capital does not significantly mitigate environmental deterioration and find a feedback causal- 
ity between human capital and ecological footprint for BRICS (Brazil, Russia, India, China, and South Africa) countries.

(iii) Transport capacity: The relevant literature focuses on the improvement of energy efficiency in transport and logistics services by addressing the substantial portion of transport-induced environmental pollution (Yu et al. 2009; IEA 2010; Zhang and Batterman 2013; Georgatzi et al. 2020). Again, income growth is one the main driver of transport energy consumption in some countries as found by $\mathrm{Lv}$ and Wu's (2019) regional study on China based on the comparisons between 1996-2005 and 2006-2015 periods. The transport effect on energy efficiency is not clear since transport itself is an energy-intensive sector with a high share (around 28\% in the 2000-2018 period) in final energy consumption in the world (IEA 2010, 2020). Li et al.'s (2021a, b) study finds complex results for different country groups over the period 2007-2019. Their findings reveal that green logistics performance enhances the environmental pollution in One Belt and Road Initiative countries, Central Asia, and the Middle East and North Africa economies, while it improves the environmental quality in Europe and East and Southeast Asia regions. These variations are also observed between the dimensions of transportation and logistics performance. For example, a study by Liu et al. (2018) uses data from 42 Asian countries between 2007 and 2016 and reveals that international shipment in logistics performance decreases $\mathrm{CO}_{2}$ emissions while timeliness of logistics intensifies the $\mathrm{CO}_{2}$ emissions.

(iv) ICT capacity: The access to digital systems and ICT devices has been growing worldwide. The spread of ICT use has set great expectations of energy efficiency improvement relying on the ICT-induced changes in social practices and socio-technical structures (Galvin 2015). However, the energy efficiency contribution of ICT adoption is questionable because of the co-occurrence of its absolute energy intensity effects and the relative energy productivity effects. For the first effect, the internet and the production, usage, and disposal of ICT goods directly consume energy. The facilitation of ICT development and sustainment of digital utilities also require energy-intensive large infrastructures. Furthermore, economic vitalization from increased ICT use may lead to increased energy consumption (the income effect). For this income mechanism of the rebound effect at both individual and country level, additional income generated through ICT-enabled energy productivity may lead to an increase in the energy demand (Takase and Murota 2004). The sec- ond effect, i.e., the substitution effect, is about the channels through which the ICT-driven digital transformation increases the total factor productivity and stimulates the transition to a service economy. The ICT-driven digital transformation decreases energy consumption by replacing energy-inefficient production technologies and energy-intensive obsolete commutations systems (Galvin 2015; Yan et al. 2018; Lange et al. 2020). However, a noteworthy fact is that ICT-led digital transition again needs more energy. Thus, the net energy efficiency effect of ICT remains conditional on the relative importance of the contradictory sequent effects. Sadorsky (2012) ascertains a positive relationship between the use of ICT components (internet, mobile phones, and computers) and electricity consumption for the 1993-2008 period of 19 emerging countries. Again, Salahuddin and Alam (2016) show that ICT use (mobile and internet use) stimulates electricity consumption in OECD countries during the period of 1985-2012. A study by Usman et al. (2021) confirms that the increased use of ICT improves energy efficiency in only India in South Asia from 1990 through 2018. On the contrary, using a 13-year (1995-2007) and 27-industry dataset of 10 OECD countries, Schulte et al. (2016) find that ICT development is associated with a significant reduction in total energy demand. For a mixed panel of 50 developed and developing countries over the 1995-2013 period, Yan et al. (2018) conclude that ICT development is significantly related to energy productivity improvement. Adopting an ICT trade approach and using panel data of six South Asian countries from 2000 to 2016, Murshed (2020) shows that ICT trade reduces energy intensity.

On the equivocalness of evidence, Takase and Murota (2004) divide the impacts of ICT investment into substitution and income effects and compare two high-income countries' possible future status. They link increasing energy consumption to economic vitalization (the income effect) while decreasing energy consumption is associated with the change in the industrial structure towards lesser energy-intensive industries (the substitution effect). Their analysis determines that the promotion of information technologies would possibly conserve more energy (the substitution effect is dominant) in Japan, whereas it might lead to increases in energy use (the income effect is dominant) for the USA. ICT adoption also interacts with the institutional framework and together mediate the relationships between resource abundance and economic growth. For example, utilizing data from 1984 to 2016 for 43 Organization of Islamic Corporation countries, Erum and Hussain (2019) demonstrate that ICT diffusion determines 
the impacts of corruption on economic growth. They affirm that natural resources impede economic growth in countries with low ICT competence, whereas the nexus is positive in high ICT diffusion countries.

(v) Institutional capacity: It is long argued that wellgoverned state intervention, strong institutions, and good democracy, which are tightly correlated, are necessary conditions to increase the environmental awareness of societies and the efficacy of environmental policies (Neumayer 2002; Castiglione et al. 2015). This mechanism is also true for energy efficiency performance within the institutional theory (Neumayer 2002; Ward 2008; Azam et al. 2021). The institutional theory argues that environmental problems have socio-economic and anthropocentric causes and effects at both the organizational and country levels (Hoffman and Jennings 2015). Over the period 1996-2010 for 33 high-income countries including advanced, emerging, and former-transition economies, Castiglione et al. (2015) confirm a negative link between the enforcement of the rule of law and environmental pollution. The resource curse hypothesis argues that natural resource-rich developing countries tend to suffer from slow economic growth because of lower institutional quality. Consistently, based on an analysis covering the 2000-2015 period, Zallé (2019) finds better control of corruption as an appropriate policy action to take advantage of natural resources in African countries. A study by Sun et al. (2019) ascertains a significant contribution of institutional quality to energy efficiency enhancement in a large sample of developed and developing countries between 1990 and 2014. Ozturk et al. (2019) also confirm that better control of corruption enhances the energy efficiency for all income groups of 60 countries during 2000-2017. By conducting a patent analysis for large multinational companies in Europe, Japan, and the USA over the period 2002-2017, Aldieri et al. (2020) find that institutional quality enhances the technical efficiency of firms through a transition from more to less pollutive technologies. Some studies, albeit fewer, find the disconnection and even undesired association between environmental quality and institutional quality. For example, using panel data of 61 countries from 2003 to 2016, Akhbari and Nejati (2019) show that corruption and anti-corruption do not affect carbon emissions in developed countries. Furthermore, using data from 66 developing countries between 1991 and 2017, Azam et al. (2021) determine institutional quality leading to increases in environmen- tal pollution caused by more consumption of energy generated from non-renewable resources.

(vi) Private sector capacity: In the business literature, organizational commitment to energy efficiency practices is no longer seen as a hindrance in reaching business targets. In this micro-level win-win approach, coherent incorporation of environmental responsibility into economic goals benefits both business and the environment (Porter and Van der Linde 1995; Shrivastava 1995; Ambec and Lanoie 2008; Brinkerink et al. 2019; Aldieri et al. 2020). However, market failures, the lack of finance, inadequate policy framework, and insufficient energy infrastructure continue to set barriers to the private sector's investment in energy efficiency. Thus, government supports are needed to facilitate the private sector's energy efficiency involvement. Meanwhile, whether private enterprises become (voluntarily) or made (by governmental policies) more energy-efficient is a longstanding debate. In the context of intrinsic versus extrinsic motivation, it is widely believed that governments are responsible to cope with environmental problems. Accordingly, most of the literature has focused on the impacts of environmental policies, rather than the possible direct impact of private sector development. In the empirical studies, the development of private sectors is represented by different indicators including financial development, stock market performance, and business environment. For the financial development pillar, Le and Ozturk's (2020) results demonstrate financial development as well as energy consumption increase $\mathrm{CO}_{2}$ emissions in 47 emerging market and developing economies between 1990 and 2014. As a country-specific study, Rohdin et al.'s (2007) questionnaire analysis shows that respondents from the Swedish foundry industry perceive the limited access to capital as the most important barrier to energy efficiency. Chang (2015) analyzes a sample of 53 countries for the period 1999-2008 and explores that, for non-high-income countries, energy consumption increases with both private and domestic credit that are used as financial development indicators. Rieger (2019) determines pro-business regulations raising $\mathrm{CO}_{2}$ emissions in developing countries during the 2005-2014 period. Besides the importance of the overall size of the private sector, the expansion of industries and enterprises also matters for their energy efficiency based on the economy of scale argument. For example, Brinkerink et al. (2019) show that Netherlands' manufacturers become more energy-efficient after their large capital expenditures over the 2000-2008 period. Martinez (2016) also shows that enterprise 
Table 2 Historical updates in the Atlas GNI per capita thresholds (current USD)

\begin{tabular}{llllll}
\hline Groups $\downarrow$ & $2000-2004$ avg & 2005-2009 avg & 2010-2014 avg & 2015-2018 avg & 2000-2018 avg.** \\
\hline LIEs & $<766$ & $<938$ & $<1,032$ & $<1,014$ & $<933$ \\
LMIEs & $766-3,039$ & $938-3,713$ & $1,032-4,069$ & $1,014-3,970$ & $933-3,683$ \\
UMIEs & $3,040-3,099$ & $3,714-11,479$ & $4,070-12,569$ & $3,971-12,285$ & $3,684-11,388$ \\
HIEs & $>9,399$ & $>11,479$ & $>12,569$ & $>12,285$ & $>11,388$ \\
\hline
\end{tabular}

* The study's country grouping is based on the average income thresholds of the 2000-2018 period Source: Elaboration based on World Bank (2021) data archive size has a positive influence on energy efficiency among German and Colombian non-energy-intensive sectors between 1998 and 2005. The international trade theory and international business literature suggest that exporting encourages energy-saving innovation at both country and firm levels. Consistently, Montalbano and Nenci (2019) provide some evidence supporting the 'learning energy efficiency by exporting' paradigm in some cases of a large sample of firms located in 30 Latin American and Caribbean countries. It is also important to note that the economic performance of enterprises may be obstructed by environmental problems (Soppelsa et al. 2021) and improved by the commitment to environmental protection (Efobi et al. 2019), which together favor the win-win strategy.

(vii) Structural change capacity: Structural change, which is commonly evaluated by the comparisons of sectoral shares in the national economy, plays a decisive role in energy efficiency. For the transition economies, structural change also contains a transformation from central planning to marketization. Cornillie and Fankhauser (2004) show that progress in enterprise restructuring is an important driver for more efficient energy consumption of the transition economies of Central and Eastern Europe and the former Soviet Union during the 1990s. Similarly, for the 1990-2010 period of different groups of the transition economies, Nepal et al.'s (2014) study confirms that transition reforms for market liberalization, financial sector development, and infrastructure improvement incite energy efficiency. Studies often support the suggestion that industrial production, on average, is less energy-efficient than the service sector. For example, Sineviciene et al. (2017) demonstrate that structural change determined by industry share in the national economy (industrialization) significantly decreases energy efficiency for the Eastern European post-communist countries during 1996-2013. Consistently, Atalla and Bean (2017) verify that economic shifts from industry to serviceled sectors improve overall energy productivity and the growth of industrial production lowers energy productivity in 39 countries during 1995-2009. Similar results are found by $\mathrm{Li}$ (2019) based on China's 1965-2017 data.

The review of the literature outlines that the findings are heterogeneous and sensitive to the proxies and measures as well as to samples and methods. The theory strongly suggests that improvements of productive capacities in socio-economic factors provide opportunities to foster environmental performance. However, there is still a lack of empirical studies investigating the socio-economic predictors of energy efficiency, particularly at the world level.

\section{Sample and data}

After excluding some countries with missing data and significant outliers, this study covers a sample of 125 economies. The study has a 19-year dataset because the PCI metrics are available only from 2000 to 2018. Based on the World Bank's Atlas method, we have distinguished these countries between four income groups by gross national income (GNI) per capita converted current United States dollars (USD). Per capita GNI computations are influenced by the changes in economic growth, inflation, exchange rates, and population, as well as methodological revisions to national accounts. Therefore, the World Bank updates annually the per capita GNI thresholds to keep the income levels fixed in real terms. The periodical averages of the annual thresholds shown in Table 2 demonstrate that the income thresholds varied considerably between 2000 and 2018 .

Large sample studies with different income groups, however, usually take an available country classification in a given year by ignoring the movements of some countries to different (upper or lower) income categories within the examined period. The considerations of threshold updates and between-groups movements are important in our case. Therefore, we have regrouped countries by GNI per capita based on the average income thresholds of the examined period (2000-2018).

The resource endowment theory indicates that the natural resource abundance of countries affects their environmental performance. Empirically, it means that resource abundance 
Table 3 Country sub-samples of the study

Low-income economies (LIEs) (12 countries)

Bangladesh, Cambodia, Democratic Republic of the Congo, Ethiopia, Kenya, Kyrgyzstan, Mozambique, Niger, Tajikistan, Tanzania, Togo, Zimbabwe

Lower-middle-income economies (LMIEs) (27 countries)

Angola, Benin, Bolivia, Cameroon, Côte d'Ivoire, Egypt, Ghana, Haiti, Honduras, India, Indonesia, Lao People's Democratic Republic, Moldova, Mongolia, Morocco, Nicaragua, Nigeria, Pakistan, Philippines, Republic of Congo, Senegal, Sri Lanka, Ukraine, Uzbekistan, Viet Nam, Yemen, Zambia

Upper-middle-income economies (UMIEs) (48 countries)

Albania, Algeria, Argentina, Armenia, Azerbaijan, Belarus, Bosnia and Herzegovina, Botswana, Brazil, Bulgaria, Chile, China, Colombia, Costa Rica, Croatia, Dominican Republic, Ecuador, El Salvador, Equatorial Guinea, Gabon, Georgia, Guatemala, Hungary, Iran, Jamaica, Jordan, Kazakhstan, Latvia, Lebanon, Lithuania, Malaysia, Mauritius, Mexico, Namibia, North Macedonia, Panama, Paraguay, Peru, Poland, Romania, Russia, South Africa, Suriname, Thailand, Tunisia, Turkey, Turkmenistan, Uruguay

High-income economies (HIEs) (38 countries)

Australia, Austria, Bahrain, Belgium, Brunei Darussalam, Canada, Cyprus, Czech Republic, Denmark, Estonia, Finland, France, Germany, Iceland, Ireland, Israel, Italy, Japan, Republic of Korea, Kuwait, Luxembourg, Malta, Netherlands, New Zealand, Norway, Oman, Portugal, Saudi Arabia, Singapore, Slovak Republic, Slovenia, Spain, Sweden, Switzerland, Trinidad and Tobago, United Arab Emirates, United Kingdom, United States

Non-renewable-resource-dependent economies (NRDEs) (33 countries)

Algeria, Angola, Azerbaijan, Bahrain, Bolivia, Botswana, Brunei Darussalam, Cameroon, Chile, Republic of Congo, Democratic Republic of the Congo, Côte d'Ivoire, Equatorial Guinea, Gabon, Ghana, Indonesia, Iran, Kazakhstan, Lao People's Democratic Republic, Mexico, Mongolia, Niger, Nigeria, Norway, Oman, Peru, Russia, Saudi Arabia, Suriname, Trinidad and Tobago, United Arab Emirates, Yemen, Zambia

should be controlled in cross-country studies (Blanco and Grier 2012; Zallé 2019; Altinoz and Dogan 2021). On the other hand, it is well evidenced that resource abundance does not necessarily mean resource dependence (Havranek et al. 2016; Hailu and Kipgen 2017; Shahbaz et al. 2019). Combining the resource abundance and resource dependence, we have designated a specific country group of nonrenewable-resource-dependent economies (NRDEs) by taking three criteria into account. Firstly, the countries are in the resource-rich group in the classification of International Monetary Fund (IMF). IMF (2012) defines a country to be resource-rich when the country has at least a $20 \%$ share of either natural resource revenue in total fiscal revenue or natural resource exports in total exports. The classification of IMF (2012) is based on the average of the 2006-2010 period which fits well the average of the period (2000-2018) of our study. Secondly, we have considered the extractives dependence index (EDI) introduced by Hailu and Kipgen (2017). EDI was measured by the economic dependence of countries on the extractive sectors consisting of oil, gas, and mineral resources. Countries in our NRDEs group have an EDI value greater than 20. Hailu and Kipgen (2017) constituted the EDI compositely based on the share of export earnings from extractives in total export earnings, the share of the revenues from extractives in total fiscal revenue, and the extractive industry value-added in GDP. Lastly, based on the UNCTAD (2021a) data and as an average of the 2000-2018 period, we have also computed the revealed comparative advantage (RCA) indices ${ }^{4}$ (greater than 2) and net export

\footnotetext{
4 The RCA index, widely known as the Balassa index, is calculated by the formula $R C A_{i j}=\left(x_{i j} / X_{i t}\right) /\left(x_{w j} / X_{w t}\right)$. For our case, $R C A_{i j}$ is the RCA index for country $i$ 's non-renewable resource product $j$, whereas
}

(positive) in crude oil (petroleum) and natural gas sectors. ${ }^{5}$ Consequently, our NRDEs are both resource-abundant and resource-dependent as well as they have both higher comparative advantage and positive net export in at least one of oil and natural gas resources. The final sampling of countries by income level and resource dependence are shown in Table 3. Methodologically, this categorization improves the within-group homogeneity and increases the comparability of the results.

This study uses these countries' time series data of energy productivity, energy intensity, GNI per capita, and productive capacities index (PCI) variables to construct a panel dataset. Energy productivity (EnProd) is measured by GDP per unit of TPES as thousand USD at constant (2015) prices. The constant (real) term better measures the true productivity by adjusting for the effects of price inflation. Energy intensity (EnInt) is gauged by TPES per capita as tons of oil equivalent. The data of both energy efficiency indicators are taken from the environment database of OECD (2021). GNI per capita (GNIpc) is measured as current USD per capita (thousand) based on the Atlas method which better captures

\footnotetext{
Footnote 4 (continued)

$x_{i j}$ and $x_{w j}$ are the values of country $i$ 's and the world's exports of product $j$, respectively. $X_{i t}$ and $X_{w t}$ refer to the total exports of the country and the world. Even though an index value greater than unity implies a revealed comparative advantage in the product, we only considered RCAs greater than 2 for a rigorous inference.

${ }^{5}$ In the Standard International Trade Classification (SITC) $\left(3^{\text {rd }}\right.$ revision), the codes of crude oil and natural gas sectors are 33-petroleum, petroleum products, and related materials (crude) and 34-natural gas (natural and manufactured).
} 
Table 4 Descriptive statistics and correlations

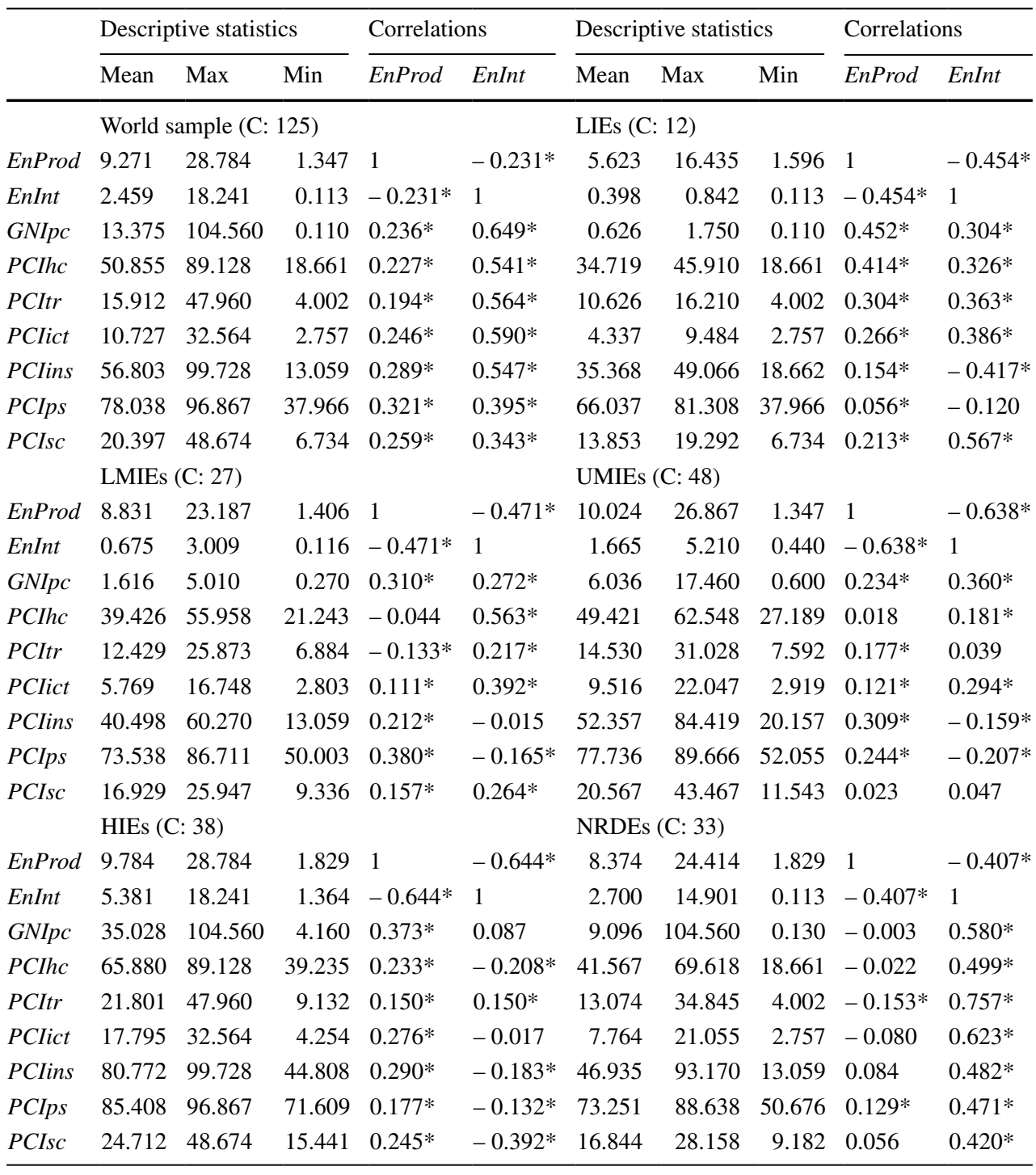

* shows the statistical significance of correlation coefficients at the level of 5\% living standards. We have selected the socio-economic components of the PCI metrics: Human capital (PCIhc), transport (PCItr), ICT (PClict), institutions (PCIins), private sector (PCIps), and structural change (PCIsc). GNIpc and PCI datasets are taken from the World Bank (2021) and UNCTAD (2021a), respectively.

\section{Descriptive statistics and correlations}

Summary descriptive statistics of variables and Pearson correlation coefficients are reported in Table 4 . At the world level, over the covered period, the mean EnProd is 9.271 thousand USD per unit of TPES varying between 28.784 (in the year 2018 of Malta from HIEs) and 1.347 (in the year 2003 of Turkmenistan from UMIEs). The mean value of EnInt is 2.459 tons of oil equivalent with a maximum value of 18.241 (in the year 2018 of Iceland from HIEs) and a minimum value of 0.113 (in the year 2011 of Niger from LIEs and NRDEs). The highest GNIpc (104.560 USD) is that of Norway (in 2014), while Ethiopia has the lowest GNIpc (110 USD in 2000).

PCI scores considerably change across sub-samples as well. The Republic of Korea has the highest (89.128 in 2018) PCIhc score, whereas Niger has the lowest index (18.661 in 2000). The USA (47.960 in 2007) and Niger (4.002 in 2001) have, respectively, the highest and lowest PCItr scores. For PCIict, Iceland (32.564 in 2018) has the best performance, while the Democratic Republic of the Congo has the worst performance (2.757 in 2000). Finland (99.728 in 2004) has the highest and Yemen (13.059 in 2018) has the lowest levels in PCIins. For PCIps scores, Iceland has the highest index (96.867 in 2006) and Tajikistan has the lowest index (37.966 in 2018). Lastly, the USA holds the highest (48.674) PCIsc score, while Ethiopia's score is the lowest (6.734 in 2000). 
Table 5 Results of cross-sectional dependence tests

\begin{tabular}{|c|c|c|c|c|c|c|}
\hline & Pesaran scaled LM & $\begin{array}{l}\text { Bias-corrected } \\
\text { scaled LM }\end{array}$ & Pesaran CD & Pesaran scaled LM & $\begin{array}{l}\text { Bias-corrected } \\
\text { scaled LM }\end{array}$ & Pesaran CD \\
\hline & World sample (C: 125) & & & LIEs (C: 12) & & \\
\hline EnProd & $471.023^{*}$ & $467.551^{*}$ & $140.767 *$ & $30.650 *$ & $30.317 *$ & $16.150^{*}$ \\
\hline EnInt & $412.303^{*}$ & $408.831^{*}$ & $34.280 *$ & $30.034 *$ & $29.701 *$ & $5.379 *$ \\
\hline GNIpc & $841.627 *$ & $838.155^{*}$ & $332.149 *$ & $84.487 *$ & $84.154 *$ & $32.033^{*}$ \\
\hline PCIhc & $778.004 *$ & $774.532 *$ & $290.510^{*}$ & $84.949 *$ & $84.616^{*}$ & $32.133^{*}$ \\
\hline PCItr & $332.901 *$ & $329.429 *$ & $95.398 *$ & $28.360 *$ & $28.027 *$ & $4.914 *$ \\
\hline PCIict & $1002.45^{*}$ & $998.975^{*}$ & $363.430 *$ & $95.649 *$ & $95.316^{*}$ & $34.114 *$ \\
\hline PCIins & $229.494 *$ & $226.022 *$ & $8.864^{*}$ & $25.776 *$ & $25.443 *$ & $3.569 *$ \\
\hline PCIps & $475.531^{*}$ & $472.058^{*}$ & $123.270^{*}$ & $51.101 *$ & $50.768 *$ & 1.493 \\
\hline \multirow[t]{2}{*}{ PCIsc } & $221.181^{*}$ & $217.709^{*}$ & $32.467 *$ & $37.632 *$ & $37.299 *$ & $14.326^{*}$ \\
\hline & LMIEs (C: 27) & & & UMIEs (C: 48) & & \\
\hline EnProd & $98.565^{*}$ & $97.815^{*}$ & $19.471 *$ & $155.079 *$ & $153.746^{*}$ & $45.909^{*}$ \\
\hline EnInt & $107.942 *$ & $107.192 *$ & $26.395^{*}$ & $146.867 *$ & $145.533^{*}$ & $55.404 *$ \\
\hline$G N I p c$ & $195.299 *$ & $194.549 *$ & $74.058 *$ & $351.809^{*}$ & $350.475^{*}$ & $133.120^{*}$ \\
\hline PCIhc & $180.421^{*}$ & $179.671^{*}$ & $68.312^{*}$ & $281.802^{*}$ & $280.469 *$ & $100.404 *$ \\
\hline PCItr & $76.487 *$ & $75.737 *$ & $13.583 *$ & $180.230 *$ & $178.897 *$ & $61.210^{*}$ \\
\hline PCIict & $223.061^{*}$ & $222.311 *$ & $79.094 *$ & $398.448^{*}$ & $397.115^{*}$ & $141.553^{*}$ \\
\hline PClins & $46.437 *$ & $45.687^{*}$ & $1.982^{*}$ & $94.380^{*}$ & $93.047^{*}$ & $2.487 *$ \\
\hline PCIps & $104.124 *$ & $103.374 *$ & $27.928 *$ & $203.907 *$ & $202.574 *$ & $55.620^{*}$ \\
\hline \multirow[t]{2}{*}{ PCIsc } & $63.019 *$ & $62.269 *$ & $14.945^{*}$ & $72.233^{*}$ & $70.899 *$ & $11.895^{*}$ \\
\hline & HIEs (C: 38) & & & NRDEs (C: 33) & & \\
\hline EnProd & $185.496^{*}$ & $184.441 *$ & $58.767 *$ & $89.104 *$ & $88.188^{*}$ & $6.232 *$ \\
\hline EnInt & $139.325^{*}$ & $138.269 *$ & $28.814 *$ & $98.285^{*}$ & $97.368 *$ & $25.538 *$ \\
\hline GNIpc & $246.723^{*}$ & $245.668^{*}$ & $98.644 *$ & $232.218^{*}$ & $231.302 *$ & $89.323 *$ \\
\hline PCIhc & $222.665^{*}$ & $221.609 *$ & $86.600 *$ & $247.485^{*}$ & $246.569^{*}$ & $92.394 *$ \\
\hline PCItr & $64.144 *$ & $63.089 *$ & $26.122 *$ & $110.054^{*}$ & $109.138^{*}$ & $38.460 *$ \\
\hline PCIict & $306.999 *$ & $305.944 *$ & $110.397 *$ & $266.009 *$ & $265.092 *$ & $95.473 *$ \\
\hline PCIins & $65.651 *$ & $64.595 *$ & $6.310^{*}$ & $63.777 *$ & $62.861 *$ & -0.217 \\
\hline PCIps & $119.145^{*}$ & $118.089 *$ & $37.983 *$ & $129.821 *$ & $128.904 *$ & $23.458 *$ \\
\hline PCIsc & $52.112^{*}$ & $51.057 *$ & $5.682^{*}$ & $42.944 *$ & $42.027 *$ & $8.607^{*}$ \\
\hline
\end{tabular}

* shows the cross-sectional dependence of the series at the level of 5\%

Additionally, correlations between energy efficiency indicators and their potential predictors vary significantly across country groups. As expected, energy productivity and energy intensity are negatively correlated, albeit not that strong, in all sub-samples.

\section{Cross-sectional dependency and stationarity diagnostics}

Stationarity, which means that disturbances of series do not depend on the observed time units, is a decisive diagnostic for the selection of an appropriate analysis method. The stationarity of series may be investigated through several panel unit root tests grouped into two generations. The first group tests assume cross-sectional independence, while the second-generation tests take possible cross-sectional dependency (CD) into account (Baltagi and Pesaran 2007; Pesaran 2021). Hence, CD, which refers to the possible spatial or spillover effects of some unobserved common factors, should be detected to choose a proper unit roots test. We have employed Pesaran's (2021) CD and scaled LM tests together with Baltagi et al.'s (2012) bias-corrected scaled LM tests to check CD. These tests are based on a null hypothesis of the absence of $\mathrm{CD}$. The results reported in Table 5 reject the null hypothesis and indicate the appropriateness of the second-generation panel unit root tests.

We have applied the cross-sectionally augmented DickeyFuller (CADF) panel unit root test (Pesaran 2007), which is widely used in the recent literature (Le and Ozturk 2020; El Menyari 2021; Li et al. 2021a, b; Mensah et al. 2021; Sahoo et al. 2021). The results reported in Table 6 reject the null hypothesis of the existence of unit roots in both detrended 
Table 6 Results of CADF panel stationarity test

\begin{tabular}{lllllll}
\hline & Detrended & Trended & Detrended & Trended & Detrended & Trended \\
\hline & World sample (C: 125) & & LIEs (C: 12) & & LMIEs (C: 27$)$ & \\
EnProd & $-5.258^{*}$ & $-5.787^{*}$ & $-4.773^{*}$ & $-5.632^{*}$ & $-4.857^{*}$ & $-5.102^{*}$ \\
EnInt & $-4.061^{*}$ & $-11.155^{*}$ & $-5.385^{*}$ & $-5.244^{*}$ & $-2.553^{*}$ & $-17.708^{*}$ \\
GNIpc & $-4.672^{*}$ & $-6.074^{*}$ & $-3.293^{*}$ & $-4.741^{*}$ & $-2.351^{*}$ & $-3.839^{*}$ \\
PCIhc & $-5.702^{*}$ & $-5.835^{*}$ & $-8.052^{*}$ & $-21.172^{*}$ & $-5.248^{*}$ & $-5.473^{*}$ \\
PCItr & $-4.858^{*}$ & $-4.888^{*}$ & $-4.516^{*}$ & $-3.902^{*}$ & $-4.119^{*}$ & $-4.317^{*}$ \\
PCIict & $-4.956^{*}$ & $-4.895^{*}$ & $-1.934^{*}$ & $-2.707^{*}$ & $-5.052^{*}$ & $-5.362^{*}$ \\
PCIins & $-6.046^{*}$ & $-6.103^{*}$ & $-2.851^{*}$ & $-2.945^{*}$ & $-6.273^{*}$ & $-5.666^{*}$ \\
PCIps & $-5.187^{*}$ & $-6.126^{*}$ & $-3.292^{*}$ & $-3.875^{*}$ & $-5.336^{*}$ & $-5.818^{*}$ \\
PCIsc & $-4.839^{*}$ & $-5.377^{*}$ & $-4.666^{*}$ & $-5.771^{*}$ & $-4.062^{*}$ & $-4.529^{*}$ \\
& UMIEs (C: 48) & & HIEs (C: 38) & & NRDEs (C: 33$)$ & \\
EnProd & $-2.684^{*}$ & $-5.097^{*}$ & $-3.035^{*}$ & $-4.955^{*}$ & $-4.156^{*}$ & $-4.358^{*}$ \\
EnInt & $-6.606^{*}$ & $-6.753^{*}$ & $-5.523^{*}$ & $-5.882^{*}$ & $-4.346^{*}$ & $-4.111^{*}$ \\
GNIpc & $-1.609^{*}$ & $-2.978^{*}$ & $-2.382^{*}$ & $-2.978^{*}$ & $-3.131^{*}$ & $-3.898^{*}$ \\
PCIhc & $-2.743^{*}$ & $-9.246^{*}$ & $-2.175^{*}$ & $-9.555^{*}$ & $-3.639^{*}$ & $-3.851^{*}$ \\
PCItr & $-4.520^{*}$ & $-4.307^{*}$ & $-5.138^{*}$ & $-5.092^{*}$ & $-4.536^{*}$ & $-4.392^{*}$ \\
PCIict & $-1.798^{*}$ & $-4.692^{*}$ & $-3.167^{*}$ & $-4.810^{*}$ & $-3.708^{*}$ & $-3.803^{*}$ \\
PCIins & $-2.640^{*}$ & $-9.638^{*}$ & $-8.821^{*}$ & $-9.742^{*}$ & $-4.446^{*}$ & $-4.224^{*}$ \\
PCIps & $-2.419^{*}$ & $-6.011^{*}$ & $-2.317^{*}$ & $-5.906^{*}$ & $-4.087^{*}$ & $-4.336^{*}$ \\
PCIsc & $-3.624^{*}$ & $-5.661^{*}$ & $-6.115^{*}$ & $-7.672^{*}$ & $-2.974^{*}$ & $-8.824^{*}$ \\
\hline
\end{tabular}

Values are cross-sectionally augmented Im-Pesaran-Shin (CIPS) statistics calculated as a simple average of individual CADF statistics

* shows the stationarity of the series at the level of 5\%. Optimal lag length varies from 1 to 3 and trended specifications and indicate stationarity of variables at the level.

\section{Hypotheses and analyses}

This study proposes five hypotheses as follows: Hypothesis 1: Country groups have significantly different levels in energy efficiency performances and socio-economic productive capacities. Hypothesis 2: Socio-economic productive capacities and per capita income significantly and differently affect energy efficiency performances of country groups. Hypothesis 3: The impacts of socio-economic productive capacities and per capita income on energy efficiency change over the energy productivity and energy intensity considerations. Hypothesis 4: Socio-economic productive capacities and per capita income may increase both energy productivity and energy intensity dimensions of energy efficiency (rebound effect). Hypothesis 5: There are feedback causalities within and between the socio-economic productive capacities and energy efficiency indicators. This study has employed different analyses to test these hypotheses.

\section{Analysis of variance}

To test the first hypothesis, an appropriate analysis of variance (ANOVA) procedure is followed. The one-way ANOVA is largely used to determine whether the means of groups are equal or different. This approach proposes the null hypothesis of equal means of compared groups. Despite the rejection of the null hypothesis indicates that at least one group is different from the others, it does not specify which group is different. Thus, the ANOVA tests are followed by a post hoc test (Pohlert 2014; Dinno 2015; Midway et al. 2020). The ordinary one-way parametric ANOVA procedure has strict assumptions of equal group size, homogenous variances, and normal distribution. Alternatively, as a rankbased nonparametric ANOVA procedure, the Kruskal-Wallis test is robust to the violations of these assumptions and less sensitive to outliers in data. Thus, the Kruskal-Wallis test performs better than the parametric alternates in the case of asymmetric populations as in our sample (Hecke 2012; Ostertagová et al. 2014). When the Kruskal-Wallis test rejects the equality of group means, Dunn's post hoc test is an appropriate nonparametric pairwise comparison (Dinno 2015; Midway et al. 2020).

We have followed a combined nonparametric ANOVA procedure of the Kruskal-Wallis and Dunn's tests. The 
Table 7 ANOVA results of comparisons of sub-samples

\begin{tabular}{|c|c|c|c|c|c|}
\hline \multirow[t]{2}{*}{ Variables } & \multirow[t]{2}{*}{ Groups } & \multirow{2}{*}{$\begin{array}{l}\text { Means } \\
\text { (level) }\end{array}$} & \multicolumn{2}{|c|}{ Multiple comparisons } & \multirow{2}{*}{$\begin{array}{l}\text { Dunn's pairwise comparisons } \\
\text { (significant comparisons only) }\end{array}$} \\
\hline & & & Means (rank) & $\begin{array}{l}\text { Kruskal- } \\
\text { Wallis stat }\end{array}$ & \\
\hline \multirow[t]{5}{*}{ EnProd } & LIEs & 5.623 & 717 & $282 *$ & \multirow{5}{*}{$\begin{array}{l}(\text { LIEs }<\text { LMIEs)*; }(\text { LIEs }<\text { UMIEs)* } \\
(\text { LIEs }<\text { HIEs)*; }(\text { LIEs }<\text { NRDEs)* } \\
(\text { LMIEs }<\text { UMIEs)*; }(\text { LMIEs }<\text { HIEs)* } \\
(\text { UMIEs }>\text { NRDEs)*; }(\text { HIEs }>\text { NRDEs)* }\end{array}$} \\
\hline & LMIEs & 8.831 & 1439 & & \\
\hline & UMIEs & 10.024 & 1726 & & \\
\hline & HIEs & 9.784 & 1629 & & \\
\hline & NRDEs & 8.374 & 1365 & & \\
\hline \multirow[t]{5}{*}{ EnInt } & LIEs & 0.398 & 374 & $1714^{*}$ & \multirow{5}{*}{$\begin{array}{l}(\text { LIEs }<\text { LMIEs)*; }(\text { LIEs }<\text { UMIEs)* } \\
(\text { LIEs }<\text { HIEs)*; }(\text { LIEs }<\text { NRDEs)* } \\
\left(\text { LMIEs }<\text { UMIEs)*; }(\text { LMIEs }<\text { HIEs })^{*}\right. \\
\left(\text { LMIEs }<\text { NRDEs)*; }(\text { UMIEs }<\text { HIEs) })^{*}\right. \\
(\text { HIEs }>\text { NRDEs)* }\end{array}$} \\
\hline & LMIEs & 0.675 & 705 & & \\
\hline & UMIEs & 1.665 & 1511 & & \\
\hline & HIEs & 5.381 & 2464 & & \\
\hline & NRDEs & 2.700 & 1440 & & \\
\hline \multirow[t]{5}{*}{ GNIpc } & LIEs & 0.626 & 266 & $2029^{*}$ & \multirow{5}{*}{ 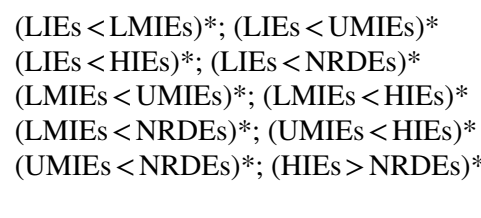 } \\
\hline & LMIEs & 1.616 & 699 & & \\
\hline & UMIEs & 6.036 & 1528 & & \\
\hline & HIEs & 35.028 & 2572 & & \\
\hline & NRDEs & 9.096 & 1336 & & \\
\hline \multirow[t]{5}{*}{ PCIhc } & LIEs & 34.719 & 510 & $1690 *$ & \multirow{5}{*}{ 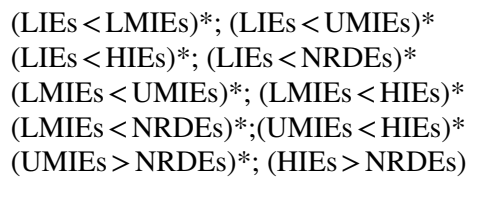 } \\
\hline & LMIEs & 39.426 & 843 & & \\
\hline & UMIEs & 49.421 & 1686 & & \\
\hline & HIEs & 65.880 & 2454 & & \\
\hline & NRDEs & 41.567 & 1035 & & \\
\hline \multirow[t]{5}{*}{ PCItr } & LIEs & 10.626 & 775 & $1226^{*}$ & \multirow{5}{*}{$\begin{array}{l}(\text { LIEs }<\text { LMIEs)*; }(\text { LIEs }<\text { UMIEs)* } \\
(\text { LIEs }<\text { HIEs)*; }(\text { LIEs }<\text { NRDEs)* } \\
\left(\text { LMIEs }<\text { UMIEs)*; }(\text { LMIEs }<\text { HIEs) })^{*}\right. \\
(\text { UMIEs }<\text { HIEs)*; })^{*} \text { UMIEs }>\text { NRDEs)* } \\
(\text { HIEs }>\text { NRDEs)* }\end{array}$} \\
\hline & LMIEs & 12.429 & 1054 & & \\
\hline & UMIEs & 14.530 & 1483 & & \\
\hline & HIEs & 21.801 & 2414 & & \\
\hline & NRDEs & 13.074 & 1108 & & \\
\hline \multirow[t]{5}{*}{ PCIict } & LIEs & 4.337 & 521 & $1519 *$ & \multirow{5}{*}{$\begin{array}{l}(\text { LIEs }<\text { LMIEs)*; })^{*} \text { LIEs }<\text { UMIEs)* } \\
(\text { LIEs }<\text { HIEs)*; }(\text { LIEs }<\text { NRDEs)* } \\
(\text { LMIEs }<\text { UMIEs)*; }(\text { LMIEs }<\text { HIEs)* } \\
(\text { LMIEs }<\text { NRDEs)*; }(\text { UMIEs }<\text { HIEs)* } \\
(\text { UMIEs }>\text { NRDEs)*; }(\text { HIEs }>\text { NRDEs)* }\end{array}$} \\
\hline & LMIEs & 5.769 & 867 & & \\
\hline & UMIEs & 9.516 & 1563 & & \\
\hline & HIEs & 17.795 & 2452 & & \\
\hline & NRDEs & 7.764 & 1193 & & \\
\hline \multirow[t]{5}{*}{ PCIins } & LIEs & 35.368 & 569 & $1606^{*}$ & \multirow{5}{*}{$\begin{array}{l}(\text { LIEs }<\text { LMIEs)*; }(\text { LIEs }<\text { UMIEs)* } \\
(\text { LIEs }<\text { HIEs)*; }(\text { LIEs }<\text { NRDEs)* } \\
(\text { LMIEs }<\text { UMIEs)*; }(\text { LMIEs }<\text { HIEs)* } \\
(\text { LMIEs }<\text { NRDEs)*; }(\text { UMIEs }<\text { HIEs)* } \\
(\text { UMIEs }>\text { NRDEs)*; })^{*} \text { HIEs }>\text { NRDEs)* }\end{array}$} \\
\hline & LMIEs & 40.498 & 894 & & \\
\hline & UMIEs & 52.357 & 1494 & & \\
\hline & HIEs & 80.772 & 2522 & & \\
\hline & NRDEs & 46.935 & 1174 & & \\
\hline \multirow[t]{5}{*}{ PCIps } & LIEs & 66.037 & 543 & $1288^{*}$ & \multirow{5}{*}{$\begin{array}{l}(\text { LIEs }<\text { LMIEs)*; })^{*} \text { LIEs }<\text { UMIEs)* } \\
(\text { LIEs }<\text { HIEs)*; }(\text { LIEs }<\text { NRDEs)* } \\
\left(\text { LMIEs }<\text { UMIEs)*; }(\text { LMIEs }<\text { HIEs) })^{*}\right. \\
(\text { UMIEs }<\text { HIEs)*; }(\text { UMIEs }>\text { NRDEs)* } \\
(\text { HIEs }>\text { NRDEs) })^{*}\end{array}$} \\
\hline & LMIEs & 73.538 & 1086 & & \\
\hline & UMIEs & 77.736 & 1536 & & \\
\hline & HIEs & 85.408 & 2393 & & \\
\hline & NRDEs & 73.251 & 1113 & & \\
\hline \multirow[t]{5}{*}{ PCIsc } & LIEs & 13.853 & 492 & $1318^{*}$ & \multirow{5}{*}{$\begin{array}{l}(\text { LIEs }<\text { LMIEs)*; })^{*} \text { LIEs }<\text { UMIEs)* } \\
(\text { LIEs }<\text { HIEs)*; }(\text { LIEs }<\text { NRDEs)* } \\
\left(\text { LMIEs }<\text { UMIEs)*; }(\text { LMIEs }<\text { HIEs) })^{*}\right. \\
(\text { UMIEs }<\text { HIEs)*; }(\text { UMIEs }>\text { NRDEs)* } \\
(\text { HIEs }>\text { NRDEs) })^{*}\end{array}$} \\
\hline & LMIEs & 16.930 & 1040 & & \\
\hline & UMIEs & 20.567 & 1725 & & \\
\hline & HIEs & 24.712 & 2293 & & \\
\hline & NRDEs & 16.844 & 1010 & & \\
\hline
\end{tabular}

* shows the statistical significance of the compared mean differences at the level of $1 \%$ 
results are reported in Table 7. The Kruskal-Wallis test finds a significant difference in all variables for all sub-samples. Dunn's pairwise comparisons also showed that each group is different from others (with a few exemptions) regarding each variable.

\section{Regression analysis}

The level-stationarity of all variables enables us to use the traditional regression modeling to test hypotheses $2-4$. Based on the hypothesized relationships, after including a regression constant $\left(\alpha_{0}\right)$ and an error term $(u)$, the final panel regression model takes the following form in Eq. (1).

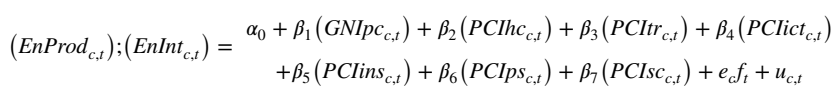

where, $c$ shows countries $(\mathrm{c}=1, \ldots, 125=\mathrm{C})$ and $t$ denotes yearly time units $(\mathrm{t}=2000, \ldots, 2018=\mathrm{T}=19)$, while $f$ is the latent common factors with $e$ varying effects. Finally, $\beta_{\mathrm{k}}$ $(\mathrm{k}=1-7)$ parameters are the coefficients to be estimated. The regression model in Eq. (1) is estimated for the world sample and five sub-sample panels.

A panel data with both cross-country and temporal dimensions may have group effects, time effects, or both. These effects are mostly modeled through the pooled regression, fixed-effects, and random-effects approaches to panel regression analysis (Ackah and Kizys 2015; Bell et al. 2019; $\mathrm{Lv}$ and $\mathrm{Wu}$ 2019). The pooled regression model builds on the country homogeneity and pools all of the included countries by averaging any unobserved (latent) heterogeneities. The pooled model is not a typical feature of our panel data. The fixed-effects model arises from the assumption that the unobserved country effects are correlated with the included regressors. Thus, the fixed-effects model is more applicable when all designated countries are sampled and potential omitted effects are likely included. The underlying assumption of the random-effect model is that the missed effects are uncorrelated with the involved regressors and they may be included in the disturbance of the model. This more likely occurs when sampled countries are randomly drawn from a large population (Greene 2012; Baltagi 2013). Besides this antecedent information, these possible effects may be determined statistically by performing several tests. These tests include the Lagrange Multiplier (LM) omitted random-effects tests of Breusch and Pagan (1980) and Honda (1985; 1991), the F-test (redundant fixed-effects test), and the Hausman's (1978) correlated random-effects test. If the null hypothesis is accepted in the LM tests and the F-test, the pooled regression is favored over the random-effects model and fixed-effects model, respectively. For the Hausman test, if the null hypothesis (the individual effects are uncorrelated with the other regressors) is accepted, the random-effects model is favored over the fixed-effects model (Greene 2012; Baltagi 2013; Ackah and Kizys 2015; Martinez 2016; Lv and $\mathrm{Wu}$ 2019). We have estimated energy efficiency models in Eq. (1) based on the inferences of these model specification tests. In all estimations, covariances and standard errors have been computed by weighting countries (period cluster) and correcting degrees of freedom to produce robustto-heteroskedasticity coefficients. The results of the panel regression estimations of energy productivity and energy intensity models are respectively reported in Tables 8 and 9 . In general, the results show that the impacts of the involved predictors tend to change across the sub-samples on a driverbarrier basis.

\section{Causality analysis}

The examination of the directions of causalities between energy use and its potential determinants, particularly economic growth (Soytas and Sari 2003; Ozturk 2010; Irandoust 2019), is an important empirical approach to design useful energy efficiency policies. In our case, as the rebound effects may be also enabled by feedback loops, it is needed to explore the directions of the relationships between energy efficiency and its regressors. Therefore, to test the last hypothesis, we have attempted to find out bidirectional causalities between energy efficiency indicators and the involved predictors. To this end, we have tested the null hypothesis of homogeneous non-causality based on the approach of Dumitrescu and Hurlin (2012), which is a common test in the recent causality literature on the heterogeneous and cross-sectionally dependent panel data (Salahuddin and Alam 2016; Le and Ozturk 2020; El Menyari 2021; Irfan 2021; Li et al. 2021a, b; Mensah et al. 2021). This procedure produces a standardized Zbar statistic which is robust to the presence of cross-country dependence and group heterogeneity. The Zbar statistics reported in Table 10 ascertain bidirectional causalities from (to) the examined predictors to (from) energy productivity and energy intensity in most cases.

\section{Results and discussion}

The ANOVA results showed that each county group is different from others (with a few exemptions) regarding all variables. The LIEs group has not only the lowest income but also the weakest performance in all socio-economic productive capacities. In general, productive capacities, as well as energy intensity, depict a monotonic function of income level since their means significantly ascend as the income levels of groups ascend. Even though it contains different countries from each income category, NRDEs' group is different from income groups in most variables. In terms of 
Table 8 Panel least squares estimate of energy productivity (EnProd) model

\begin{tabular}{|c|c|c|c|c|c|c|}
\hline $\begin{array}{l}\text { Samples } \rightarrow \\
\downarrow \text { Predictors }\end{array}$ & World & LIEs & LMIEs & UMIEs & HIEs & NRDEs \\
\hline GNIpc & $\begin{array}{l}0.008 \\
(0.008)\end{array}$ & $\begin{array}{l}2.145^{*} \\
(0.547)\end{array}$ & $\begin{array}{l}0.466^{*} \\
(0.148)\end{array}$ & $\begin{array}{l}0.029 \\
(0.054)\end{array}$ & $\begin{array}{l}0.020 * * \\
(0.009)\end{array}$ & $\begin{array}{l}-0.050^{*} \\
(0.015)\end{array}$ \\
\hline PCIhc & $\begin{array}{l}0.034 * * \\
(0.014)\end{array}$ & $\begin{array}{l}0.075 * \\
(0.027)\end{array}$ & $\begin{array}{l}-0.064 * * \\
(0.030)\end{array}$ & $\begin{array}{l}-0.126^{*} \\
(0.035)\end{array}$ & $\begin{array}{l}0.108^{*} \\
(0.022)\end{array}$ & $\begin{array}{l}0.010 \\
(0.034)\end{array}$ \\
\hline PCItr & $\begin{array}{l}-0.049 * * \\
(0.020)\end{array}$ & $\begin{array}{l}-0.001 \\
(0.027)\end{array}$ & $\begin{array}{l}-0.109^{*} \\
(0.025)\end{array}$ & $\begin{array}{l}0.073 * * \\
(0.031)\end{array}$ & $\begin{array}{l}-0.149 * \\
(0.036)\end{array}$ & $\begin{array}{l}-0.092 * \\
(0.028)\end{array}$ \\
\hline PCIict & $\begin{array}{l}0.229^{*} \\
(0.018)\end{array}$ & $\begin{array}{l}-0.257^{* *} \\
(0.108)\end{array}$ & $\begin{array}{l}0.251^{*} \\
(0.051)\end{array}$ & $\begin{array}{l}0.243 * \\
(0.045)\end{array}$ & $\begin{array}{l}0.182 * \\
(0.031)\end{array}$ & $\begin{array}{l}0.159^{*} \\
(0.035)\end{array}$ \\
\hline PCIins & $\begin{array}{l}0.063^{*} \\
(0.010)\end{array}$ & $\begin{array}{l}0.004 \\
(0.020)\end{array}$ & $\begin{array}{l}0.022 \\
(0.020)\end{array}$ & $\begin{array}{l}0.086^{*} \\
(0.015)\end{array}$ & $\begin{array}{l}0.009 \\
(0.021)\end{array}$ & $\begin{array}{l}0.092 * \\
(0.023)\end{array}$ \\
\hline PCIps & $\begin{array}{l}-0.016 \\
(0.013)\end{array}$ & $\begin{array}{l}-0.033^{* * *} \\
(0.019)\end{array}$ & $\begin{array}{l}0.075^{*} \\
(0.027)\end{array}$ & $\begin{array}{l}-0.006 \\
(0.024)\end{array}$ & $\begin{array}{l}-0.181 * \\
(0.036)\end{array}$ & $\begin{array}{l}0.055^{* *} \\
(0.025)\end{array}$ \\
\hline PCIsc & $\begin{array}{l}0.061^{*} \\
(0.022)\end{array}$ & $\begin{array}{l}0.147^{*} \\
(0.047)\end{array}$ & $\begin{array}{l}0.013 \\
(0.061)\end{array}$ & $\begin{array}{l}0.093 * * \\
(0.042)\end{array}$ & $\begin{array}{l}0.039 \\
(0.033)\end{array}$ & $\begin{array}{l}-0.173^{* *} \\
(0.075)\end{array}$ \\
\hline \multirow[t]{2}{*}{ Constant } & $\begin{array}{l}2.144 * * * \\
(1.126)\end{array}$ & $\begin{array}{l}2.811 \\
(1.722)\end{array}$ & $\begin{array}{l}3.890 * * * \\
(2.106)\end{array}$ & $\begin{array}{l}6.726^{*} \\
(2.226)\end{array}$ & $\begin{array}{l}15.782 * \\
(3.437)\end{array}$ & $\begin{array}{l}2.950 \\
(2.415)\end{array}$ \\
\hline & \multicolumn{6}{|c|}{ Goodness-of-fit and model specification statistics } \\
\hline $\begin{array}{l}R^{2} ; \\
\text { Adjusted } R^{2}\end{array}$ & $\begin{array}{l}0.903 \\
0.898\end{array}$ & $0.515 ; 0.499$ & $0.314 ; 0.305$ & $\begin{array}{l}0.890 \\
0.883\end{array}$ & $0.345 ; 0.339$ & $\begin{array}{l}0.830 \\
0.819\end{array}$ \\
\hline$F$-stat & $159.887 *$ & $33.363^{*}$ & $33.058^{*}$ & $128.849 *$ & $53.792 *$ & $73.508^{*}$ \\
\hline Breusch-Pagan LM & $15,508.54 *$ & $1500.23 *$ & $2825.930 *$ & $5450.898^{*}$ & $4570.082^{*}$ & $3168.068^{*}$ \\
\hline Honda LM & $124.533^{*}$ & $38.733^{*}$ & $53.159 *$ & $73.830^{*}$ & $67.602 *$ & $56.286^{*}$ \\
\hline$F$-test & $145.715^{*}$ & $309.522 *$ & $104.861 *$ & $113.029 *$ & $129.674 *$ & $77.918^{*}$ \\
\hline Hausman test & $45.451^{*}$ & 2.519 & 8.745 & $13.821 * *$ & 10.288 & $12.076^{* * *}$ \\
\hline Estimated effect & Fixed-effect & Random-effect & Random-effect & Fixed-effect & Random-effect & Fixed-effect \\
\hline
\end{tabular}

$*, * *$, and $* * *$ show the statistical significance of the estimated regression coefficients at the levels of $1 \%, 5 \%$, and $10 \%$, respectively. Panel corrected (cross-section weighed and degrees of freedom-corrected) robust standard errors are in parentheses

productive capacities, NRDEs' group is strictly surpassing LIEs' sub-sample but underperforming HIEs' sub-sample. The productive capacities levels of NRDEs' sub-sample are more similar to that of UMIEs' group. Relatively greater mean values of both energy productivity and energy intensity imply the possibility of the rebound effect notably in UMIEs and HIEs. Overall, the ANOVA results support the first hypothesis as we found that country groups have significantly different levels in energy efficiency performances and socio-economic productive capacities. This threshold effect of income is in line with that of Deichmann et al. (2018).

Statistically significant regression coefficients in Tables 8 and 9 reveal that per capita GNI is positively associated with energy productivity in all income groups. This result is in line with the findings of Atalla and Bean (2017) and Deichmann et al. (2018). In general, the magnitudes of the positive income effect on energy productivity decline gradually from LIEs to HIEs, albeit statistical insignificance in the case of UMIEs. We found a negative association between per capita GNI and energy productivity for NRDEs. Growth in GNI per capita tends to enlarge energy intensity for middle-income countries and NRDEs.
These findings of changing income elasticities concur with that of Steinberger and Krausmann (2011) and Chang (2015). Overall, our findings show that income growth increases both energy efficiency and energy intensity in general. This finding confirms the results of Sineviciene et al. (2017) and indicates the presence of an offsetting mechanism raised by rebound effects. Brockway et al.'s (2021) review of 33 studies underlined these economywide rebound effects as they typically exceeded $50 \%$.

The increased productive capacity in human capital stimulates energy efficiency by leading to higher energy productivity and lower energy intensity for LIEs and HIEs. Considered the adverse link between energy efficiency and environmental pollution, these results support that of Pata et al. (2021). However, for the middle-income groups, higher human capital capacity means lesser energy efficiency. We evidenced a negative impact from the growth of human capital to energy intensity in the case of NRDEs. From the resource dependence approach, this result provides some support to that of Zalle (2019). Higher transport capacity is not good for energy productivity in sub-samples except for UMIEs. Moreover, it tends to increase energy intensity for 
Table 9 Panel least squares estimate of energy intensity (EnInt) model

\begin{tabular}{|c|c|c|c|c|c|c|}
\hline $\begin{array}{l}\text { Samples } \rightarrow \\
\downarrow \text { Predictors }\end{array}$ & World & LIEs & LMIEs & UMIEs & HIEs & NRDEs \\
\hline GNIpc & $\begin{array}{l}0.002 \\
(0.004)\end{array}$ & $\begin{array}{l}0.007 \\
(0.027)\end{array}$ & $\begin{array}{l}0.075^{*} \\
(0.015)\end{array}$ & $\begin{array}{l}0.060^{*} \\
(0.010)\end{array}$ & $\begin{array}{l}0.004 \\
(0.005)\end{array}$ & $\begin{array}{l}0.030^{*} \\
(0.008)\end{array}$ \\
\hline PCIhc & $\begin{array}{l}-0.021^{*} \\
(0.007)\end{array}$ & $\begin{array}{l}-0.003^{* *} \\
(0.001)\end{array}$ & $\begin{array}{l}0.017 * \\
(0.003)\end{array}$ & $\begin{array}{l}0.015^{*} \\
(0.005)\end{array}$ & $\begin{array}{l}-0.055^{*} \\
(0.016)\end{array}$ & $\begin{array}{l}-0.023^{* *} \\
(0.012)\end{array}$ \\
\hline PCItr & $\begin{array}{l}0.029 * \\
(0.011)\end{array}$ & $\begin{array}{l}0.005^{*} \\
(0.001)\end{array}$ & $\begin{array}{l}0.007 * \\
(0.003)\end{array}$ & $\begin{array}{l}0.012^{*} \\
(0.004)\end{array}$ & $\begin{array}{l}0.032 \\
(0.026)\end{array}$ & $\begin{array}{l}-0.036^{* * *} \\
(0.021)\end{array}$ \\
\hline PClict & $\begin{array}{l}0.024^{*} \\
(0.009)\end{array}$ & $\begin{array}{l}0.027 * \\
(0.006)\end{array}$ & $\begin{array}{l}-0.030^{*} \\
(0.008)\end{array}$ & $\begin{array}{l}-0.012 \\
(0.008)\end{array}$ & $\begin{array}{l}0.034 * * * \\
(0.019)\end{array}$ & $\begin{array}{l}0.064 * \\
(0.019)\end{array}$ \\
\hline PClins & $\begin{array}{l}-0.001 \\
(0.004)\end{array}$ & $\begin{array}{l}0.0003 \\
(0.001)\end{array}$ & $\begin{array}{l}-0.001 \\
(0.002)\end{array}$ & $\begin{array}{l}-0.004 \\
(0.003)\end{array}$ & $\begin{array}{l}-0.016 \\
(0.018)\end{array}$ & $\begin{array}{l}-0.010 \\
(0.008)\end{array}$ \\
\hline PCIps & $\begin{array}{l}-0.006 \\
(0.005)\end{array}$ & $\begin{array}{l}0.002 * * \\
(0.001)\end{array}$ & $\begin{array}{l}0.002 \\
(0.002)\end{array}$ & $\begin{array}{l}-0.002 \\
(0.005)\end{array}$ & $\begin{array}{l}-0.050 * * * \\
(0.028)\end{array}$ & $\begin{array}{l}-0.003 \\
(0.006)\end{array}$ \\
\hline PCIsc & $\begin{array}{l}0.004 \\
(0.008)\end{array}$ & $\begin{array}{l}-0.008^{*} \\
(0.003)\end{array}$ & $\begin{array}{l}-0.0003 \\
(0.007)\end{array}$ & $\begin{array}{l}0.008 \\
(0.009)\end{array}$ & $\begin{array}{l}-0.022 \\
(0.017)\end{array}$ & $\begin{array}{l}-0.030 \\
(0.021)\end{array}$ \\
\hline \multirow[t]{2}{*}{ Constant } & $\begin{array}{l}3.223^{*} \\
(0.601)\end{array}$ & $\begin{array}{l}0.289^{*} \\
(0.079)\end{array}$ & $\begin{array}{l}-0.128 \\
(0.215)\end{array}$ & $\begin{array}{l}0.687 \\
(0.428)\end{array}$ & $\begin{array}{l}13.583^{*} \\
(3.381)\end{array}$ & $\begin{array}{l}4.618^{*} \\
(0.794)\end{array}$ \\
\hline & \multicolumn{6}{|c|}{ Goodness-of-fit and model specification statistics } \\
\hline $\begin{array}{l}R^{2} ; \\
\text { Adjusted } R^{2}\end{array}$ & $0.968 ; 0.966$ & $0.438 ; 0.420$ & $0.955 ; 0.952$ & $0.947 ; 0.943$ & $\begin{array}{l}0.928 \\
0.924\end{array}$ & $0.965 ; 0.963$ \\
\hline$F$-stat & 511.059 & $24.472 *$ & $309.894 *$ & $280.864 *$ & $199.619 *$ & $420.672 *$ \\
\hline Breusch-Pagan LM & $15,775.54^{*}$ & $1252.734^{*}$ & $3034.168^{*}$ & $5911.520^{*}$ & $4643.822^{*}$ & $2450.370^{*}$ \\
\hline Honda LM & $125.601 *$ & $35.394 *$ & $55.083 *$ & $76.886^{*}$ & $68.146^{*}$ & $49.501 *$ \\
\hline$F$-test & $271.178^{*}$ & $271.734^{*}$ & $189.105^{*}$ & $209.739 *$ & $168.135^{*}$ & $190.319 *$ \\
\hline Hausman test & $128.687^{*}$ & 7.289 & $17.964 * *$ & $25.816^{*}$ & $12.884 * * *$ & $105.073^{*}$ \\
\hline Estimated effect & Fixed-effect & Random-effect & Fixed-effect & Fixed-effect & Fixed-effect & Fixed-effect \\
\hline
\end{tabular}

$*$, **, and *** show the statistical significance of the estimated regression coefficients at the levels of $1 \%, 5 \%$, and $10 \%$, respectively. Panel corrected (cross-section weighed and degrees of freedom-corrected) robust standard errors are in parentheses

all income groups. This evidence underlines the necessity of energy-saving transport modes and green logistics practices as evidenced by Li et al. (2021a, b). However, we found a negative nexus between transport capacity and energy intensity for NRDEs, revealing that transport advancement may help in the mitigation of energy intensity even in resourcedependent countries where energy prices, on average, are relatively lower. Higher ICT capacity improves energy productivity for the sub-samples (except for LIEs). This result is consistent with the conclusion of Yan et al. (2018). Nevertheless, ICT capacity-energy intensity nexus is found positive (except for middle-income groups). This supports the findings of Sadorsky (2012) and Salahuddin and Alam (2016) but contradicts that of Schulte et al. (2016) and Murshed (2020).

Institutional capacity is positively associated with energy productivity for NRDEs, as well as for UMIEs, but it does not have a significant effect on energy intensity in any case. This neutral effect is similar to that of Akhbari and Nejati (2019) but contradicts both evidence that reveals either a positive (Ozturk et al. 2019; Sun et al. 2019) or negative (Azam et al. 2021) relationship between different institutional quality and resource efficiency indicators. An increase in private sector capacity improves energy productivity in LMIEs and NRDEs, while it worsens energy productivity in LIEs and HIEs. The first case supports the findings of Rohdin et al.'s (2007) study. Moreover, the development of private sectors raises energy intensity in LIEs, confirming the results of Chang (2015) and Rieger (2019) from energy consumption and environmental pollution perspectives, respectively.

The structural change supports the energy productivity performance of LIEs and UMIEs, while it impedes NRDEs' energy productivity. The structural change also means a lesser energy intensity for LIEs. The positive nexus between structural change and energy efficiency improvement supports the findings of Cornillie and Fankhauser (2004), Nepal et al. (2014), and Sineviciene et al. (2017) who assessed structural change by different indicators.

Overall, improvements in productive capacities of some socio-economic indicators are found with potential rebound effects, which indicate that some or all of the realized energy productivity gains may be counterbalanced by increases in energy intensity, and vice versa. Similar mechanisms of the 
Table 10 Results of Dumitrescu-Hurlin pairwise causality test (Zbar statistics)

\begin{tabular}{|c|c|c|c|c|c|c|}
\hline $\begin{array}{l}\text { Samples } \rightarrow \\
\downarrow \text { Null hypothesis }\end{array}$ & World & LIEs & LMIEs & UMIEs & HIEs & NRDEs \\
\hline & \multicolumn{6}{|c|}{ Causalities between energy productivity (EnProd) and predictors } \\
\hline GNIpc $\nrightarrow$ EnProd & $10.567 *$ & $4.250 *$ & $6.381 *$ & $7.627 *$ & $2.826^{*}$ & $7.211 *$ \\
\hline EnProd $\nrightarrow$ GNIpc & $5.595^{*}$ & $4.331 *$ & $3.616^{*}$ & $3.267 *$ & 0.994 & $4.203 *$ \\
\hline PCIhc $\nrightarrow$ EnProd & $7.937^{*}$ & $4.265^{*}$ & 0.705 & $5.974 *$ & $4.690 *$ & $2.818^{*}$ \\
\hline EnProd $\nrightarrow$ PCIhc & $3.996^{*}$ & -0.793 & $3.997 *$ & $2.291 * *$ & $1.749 * * *$ & $2.919 *$ \\
\hline PCItr $\nrightarrow$ EnProd & $5.903 *$ & $3.156^{*}$ & 1.564 & $4.823^{*}$ & $2.193 * *$ & $4.129 *$ \\
\hline EnProd $\nrightarrow$ PCItr & $5.030^{*}$ & 0.233 & 1.571 & $5.305^{*}$ & $1.705 * * *$ & 0.297 \\
\hline PClict $\nrightarrow$ EnProd & $9.672^{*}$ & $2.371 * *$ & $3.793 *$ & $7.326^{*}$ & $4.779 *$ & $8.946^{*}$ \\
\hline EnProd $\nrightarrow$ PCIict & $7.061^{*}$ & 1.237 & $7.513^{*}$ & $4.640^{*}$ & 0.563 & $4.551^{*}$ \\
\hline PCIins $\nrightarrow$ EnProd & $2.397 * *$ & 0.195 & $3.871^{*}$ & 0.803 & 0.072 & $2.317 * *$ \\
\hline EnProd $\nrightarrow$ PCIins & $6.180^{*}$ & $2.302 * *$ & $2.592 *$ & $4.190 *$ & $3.021 *$ & $2.881 *$ \\
\hline PCIps $\nrightarrow$ EnProd & $4.637^{*}$ & $2.119 * *$ & $3.379^{*}$ & $2.227 * *$ & $1.868 * * *$ & $2.147 * *$ \\
\hline EnProd $\nrightarrow$ PCIps & $6.612^{*}$ & $6.882 *$ & 0.835 & $1.765 * * *$ & $5.438 *$ & $2.839 *$ \\
\hline PCIsc $\nrightarrow$ EnProd & $5.746^{*}$ & $3.848 *$ & $3.221^{*}$ & $3.447 *$ & $1.669 * * *$ & $1.771 * * *$ \\
\hline EnProd $\nrightarrow$ PCIsc & $7.552^{*}$ & $2.301 * *$ & $6.244 *$ & $2.991 *$ & $3.778 *$ & $5.060 *$ \\
\hline \multicolumn{7}{|c|}{ Causalities between energy intensity (EnInt) and predictors } \\
\hline GNIpc $\nrightarrow$ EnInt & $13.323 *$ & $3.310^{*}$ & $7.288^{*}$ & $4.734 *$ & $10.840^{*}$ & $7.106^{*}$ \\
\hline EnInt $\nrightarrow$ GNIpc & $5.189^{*}$ & $2.886^{*}$ & $2.198 * *$ & $5.283 *$ & 0.000 & $4.495^{*}$ \\
\hline$P C I h c \nrightarrow$ EnInt & $7.989^{*}$ & $2.507 * *$ & $3.454^{*}$ & $2.721^{*}$ & $7.112^{*}$ & $1.695 * * *$ \\
\hline EnInt $\nrightarrow$ PCIhc & $7.110^{*}$ & -1.416 & $3.708^{*}$ & $5.995^{*}$ & $3.829 *$ & $5.216^{*}$ \\
\hline PCItr $\nrightarrow$ EnInt & $7.859^{*}$ & $2.056^{* *}$ & $2.114 * *$ & $6.604 *$ & $3.894 *$ & $4.350 *$ \\
\hline EnInt $\nrightarrow$ PCItr & $6.762^{*}$ & $1.984 * *$ & 1.082 & $4.812^{*}$ & $4.829 *$ & $3.640 *$ \\
\hline PClict $\nrightarrow$ EnInt & $14.359 *$ & $3.734 *$ & $6.281 *$ & $6.193 *$ & $11.690^{*}$ & $10.117 *$ \\
\hline EnInt $\nrightarrow$ PCIict & $5.898^{*}$ & $3.544 *$ & $4.274 *$ & $4.252 *$ & 0.325 & $6.145^{*}$ \\
\hline PCIins $\nrightarrow$ EnInt & $2.077 * *$ & -0.539 & $1.884 * * *$ & 1.130 & 1.211 & $1.792 * * *$ \\
\hline EnInt $\nrightarrow$ PCIins & $4.664^{*}$ & $1.706^{* *}$ & $1.769 * * *$ & $2.671^{*}$ & $3.008^{*}$ & $2.582 *$ \\
\hline PCIps $\nrightarrow$ EnInt & $12.296^{*}$ & $4.817 *$ & $8.581^{*}$ & $2.656^{*}$ & $9.375^{*}$ & $6.991 *$ \\
\hline EnInt $\nrightarrow$ PCIps & $3.837^{*}$ & 1.483 & 1.115 & $4.091 *$ & 0.589 & $2.524 * *$ \\
\hline PCIsc $\nrightarrow$ EnInt & $4.342^{*}$ & 0.794 & $4.540^{*}$ & 0.420 & $3.130^{*}$ & $2.209 * *$ \\
\hline EnInt $\nrightarrow$ PCIsc & $5.283^{*}$ & 1.148 & $4.239^{*}$ & $2.737 *$ & $2.288^{* *}$ & $1.991 * *$ \\
\hline
\end{tabular}

$*$, **, and *** show the statistical significance of causalities at the levels of $1 \%, 5 \%$, and $10 \%$, respectively. Lag length is 2 rebound effects are also explained by Galvin (2015) and Lange et al. (2020). In general, our regression results support the relevant hypotheses. For the second hypothesis, the regression coefficients, particularly that of the energy productivity model, were commonly significant. The signs of the coefficients of some predictors also changed across country groups. The third hypothesis is supported as the impacts of the examined predictors of energy efficiency change over the energy productivity and energy intensity considerations. Again, the evidenced rebound effects provide some support for the fourth hypothesis.

The significant causalities reveal two-way causalities between per capita GNI and energy efficiency indicators (except for HIEs). Albeit the lack of a systematic conclusion, these feedback loops do not contradict the results of Esseghir and Khouni (2014), Castiglione et al. (2015), Li et al. (2021a, b), and Nathaniel et al. (2021). More specifically, the evidenced bidirectional causalities are in line with the results of Irfan (2021) who estimated a bidirectional causality between economic growth and energy efficiency for 34 developing economies. Given the close link between energy efficiency and carbon emissions, the two-way causalities give some support to the findings of $\mathrm{Li}$ et al. (2021a, b), who unveiled a feedback causality between economic growth and $\mathrm{CO}_{2}$ emissions. Again, the one-way causality running from per capita GNI to energy intensity in HIEs is consistent with the results of Soytas and Sari (2003), who found a unidirectional causality from GDP to energy consumption for some developed countries. Again, the causality results mostly support the last hypothesis. 


\section{Conclusion}

Engagement in energy efficiency efforts provides many benefits in all contexts from individuals and households to countries and the world. From the policy perspective to environmental issues, efficient use of limited energy resources is the responsibility of all countries. Notwithstanding, global energy efficiency improvement in practice is not at an optimal level. From the research perspective, despite the technically clear predictions in the theory, the available empirical findings on the determinants of energy efficiency provide scarce and inconsistent evidence. So far, some barriers and drivers of energy efficiency have been identified at both country and cross-country levels, albeit without consensus. The effects of countries' socioeconomic productive capacities on their energy efficiency trajectories are decisive but often underrepresented. This ignorance may explain some of the unsuccess of the local and global energy efficiency policies built on the available unclear evidence.

Addressing the shortcomings of the relevant literature, this study examined the impacts of socio-economic productive capacities, as well as per capita income, on energy efficiency in a large sample of 125 countries. The study considered the productive capacities in human capital, transport, ICT, institutions, private sector, and structural change to investigate (i) whether the socio-economic productive capacities and energy efficiency performances differ across country groups, (ii) how the examined predictors affect energy efficiency performances of country groups, (iii) to what extent the impacts of the considered predictors change over the energy productivity and energy intensity, (iv) which factors cause a rebound effect by increasing (or decreasing) both energy productivity and energy intensity, and (v) whether there are feedback loops within and between the socio-economic capacities and energy efficiency indicators. To answer these hypothesized questions, energy efficiency was assessed by energy productivity (output per unit of total primary energy supply) and energy intensity (total primary energy supply per capita). The world sample was also divided into low-income, lowermiddle-income, upper-middle-income, high-income, and non-renewable-resource-dependent economies. Accordingly, the ANOVA, regression modeling, and causality analysis were applied to a cross-country dependent and stationary panel dataset from 2000 to 2018 .

\section{Findings and implications}

The results of the ANOVA procedure confirmed that country groups with higher (lower) income levels also have higher (lower) energy intensity and socio-economic productive capacities. This pattern reveals a linear monotonic function in the between-group context. For the within-group effects, we applied linear regression analysis. The regression estimations of two energy efficiency performance measures (higher energy productivity and lower energy intensity) showed that socio-economic factors drove energy efficiency with varied effects for different country groups. To explore the directions of the effects, we also employed a causality test which established bidirectional causalities between energy efficiency and its predictors in most cases. Group-specific findings and the relevant implications of the study are as follows.

(i) Low-income economies (LIEs): The LIEs' group has the lowest levels in all included variables. Per capita income growth stimulates energy productivity most for this group. This evidence implies that low-income countries may get important energy productivity gains from sound economic growth projects. The prevalent poverty, low living standards, and persistently high unemployment, as well as huge inequalities in the share of limited prosperity and energy sources, are the main problems in many low-income countries. For these problems, the encouragement of human capital investment is seen as crucial. Our findings show that increased human capital capacity also improves overall energy efficiency. This is another reason to prompts policy-makers in these countries to involve more in the human capital practices such as quality education and training, better health services, and increased research and development activities.

Even though transport and ICT enhancement, as well as the development of the private sector, are other urgent needs for spurring progress on economic activities in low-income countries, all these variables were negatively associated with energy efficiency in our LIEs case. These countries, in general, have been facing various challenges from the carbonized obsolete transport and slow pace of ICT-based digital transformation. Thus, decision-makers should try to adopt sound policies to improve transport quality and ICT adoption. Given the very limited availability and affordability of energy, these policies also need to consider energy efficiency. On the other hand, many governments focus on the employment and income contributions of private sector development neglecting energy efficiency. The lack of stringent environmental policies may also be jeopardizing the energy efficiency motivations in private sectors. Therefore, governments in LIEs need to design an inclusive policy mechanism to accelerate the private sector's adoption of energy efficient technologies. To this end, both incentive and punitive instruments of energy efficiency policies may be put depending on the energy efficiency performance of 
private enterprises. We found a contribution from structural change to energy efficiency, suggesting an overall relocation of resources from less productive and low energy-efficient to more productive and high energy-efficient economic activities in these countries. This structural transformation needs some additional institutional reforms and tailored industrial policies accompanied by inclusive human capital development initiatives.

(ii) Lower-middle-income (LMIEs) and upper-middleincome economies (UMIEs): Energy efficiency trajectories of middle-income countries may shed light on future directions of low-income countries. For the middle-income groups, income growth has two contradicting impacts on energy efficiency as it tends to enhance both energy productivity and energy intensity. This offset mechanism (rebound effect) can be turned into net energy efficiency gains through investing in energy-saving technologies in the production sector and changing consumption patterns of individuals. Since rebound effects may erode the energy savings from improved energy efficiency, the production and consumption of energy-intensive goods and services may be taxed to demotivate unnecessary energy consumption.

Recently, middle-income countries, which also include emerging economies, have improved their human capital. However, the increased human capital capacity was found as a barrier to energy efficiency for these countries. This finding can be explained by the dynamic interaction between human capital and energy intensity: in the lower level of human capital, the energy demand is relatively lower, but after some level, human capital is improved by using more energy. Furthermore, the negative nexus between energy productivity and human capital is related to the overall energy-dependent production structure of these relatively fast-industrializing countries. Human capital development is an important driver of energy-intensive industrial competitiveness in these countries. Human capital components such as education, training, and research-development practices may be redesigned to include environmental awareness, for example by educating people about the environmental consequences of their lifestyle choices. This suggestion applies to other country groups, as well.

Improvement in ICT productive capacities of middleincome countries was found as a driver of energy productivity, while it also reduces energy intensity for lower-middle-income countries. This evidence indicates the potential benefits from the integration of digital transformation into long-term energy efficiency strategies. In particular, the governments should incite the ICT transformation by motivating the use of ICT components and providing better ICT infrastructures. While doing so, governments, themselves, should adopt energy efficiency practices and make energy-efficient ICT devices cheaper than the energy-intensive alternates. Although these countries, on average, have been making considerable efforts to improve their transport capacity and logistics performance, higher transport productive capacity was found with an energy-intensifying effect. As in almost all countries, petroleum fuels remain the dominant energy source in middle-income countries because of the advantages of low cost and high market availability. This underlines the need for energy-saving transportation practices (green transport and green logistics) which will also stimulate energy productivity for upper-middle-income countries. Besides, only the upper-middle-income countries' group has a positive nexus between transport capacity and energy productivity. This evidence may be explained by the relatively higher productivity level and ongoing structural transitions. These countries have been increasingly involving in the improvement of transports and logistics infrastructures to connect producers and consumers with international markets. Our evidence shows that these practices improve energy productivity and suggests more investment in transport capacity improvement.

The results changed considerably for the lower-middleincome and upper-middle-income groups. Therefore, given a large number of countries in these groups, prospective world-sample studies may consider classifying middleincome countries into more sub-categories by narrowing the income thresholds.

(iii) High-income economies (HIEs): For the high-income countries' sub-sample, which has the highest levels in all socio-economic capacities, income growth means higher energy productivity. This group also has the highest level of energy intensity. The neutrality of income on energy intensity indicates the absence of the trade-off effect and sets promising decoupling expectations about the future of energy demand. The high-income group has by far the highest level of human capital and gets significant energy efficiency benefits from the increased human capital capacity. Therefore, inclusive policies in these countries should keep improving the knowledge and skills in educational institutions. Overall education should be also linked to research and development projects about energy efficiency. Increased ICT capacity has a contribution to energy productivity but also increases energy intensity. The first finding indicates the importance of supporting the production systems by ICT-based digital transformation. The latter finding reveals a rebound effect and underlines the necessity of the replacement of the existing ICT components with more energy-efficient ones. Alternatively, binding energy standards enforced by taxes or fines may 
also discourage the excessive use of energy-intensive ICTs.

High-income countries should keep promoting the development of private sectors to reduce energy intensity. However, private sectors should be controlled and motivated to be more energy-productive as we found higher private sector capacity hindering energy productivity. These countries may also be attracting energy-inefficient investments from other countries. Thus, the enforcement of stringent energy policies may help in improving energy efficiency transformation in the private sector and in hindering the potential 'race to the bottom' competition in the domestic business environment. Production activities in high-income countries are strongly linked to transportation within global supply chains. These countries both produce and use transport equipment intensively. Given the evidenced negative nexus between transport capacity and energy productivity, highincome countries need to promote the adoption of more energy-efficient technologies in both the production and use of transport equipment. While doing so, these countries may also introduce new energy standards in transportation modes to vitalize the demand for energy-efficient transport. From the research perspective, again, world sample studies may consider different high-income categories such as lower-high-income and upper-high-income to have a more homogeneous income designation.

(iv) Non-renewable-resource-dependent economies (NRDEs): The case of the NRDEs sub-sample enabled us to control the relationships for resource dependence. Growth of per capita income reduces energy productivity for only this group. Furthermore, higher per capita income was found intensifying energy use. These two findings exhibit a trade-off between economic growth and energy efficiency. In these countries, economic activities and income heavily rely on extractive resources. Even though degrowth will improve energy efficiency in these countries, it is not an energy efficiency strategy. The feasible implication is to redesign economic growth strategies towards energy efficiency. A structural change to non-resource industrial development and product diversification will help these counties to decouple their economic growth from the exploitation of energy sources. The resource sectors should not be necessarily shrunk but their relative share in domestic income should be reduced with the rise of non-resource sectors. These countries' group has the second-highest level in energy intensity after high-income economies' group. For the positive nexus amid income and energy intensity, practical oil taxes and energy standards may be applied to a wide range of society from individual consumption and buildings to enterprises and governmental institutions. Furthermore, these tax revenues may be used to incite non-resource sectors and to mitigate environmental pollution.

Since the human capital-energy intensity nexus is negative, resource-dependent countries may ease energy intensity by investing in education/training, skill/talent development, and research activities, as well as in better health system practices. Improved transport capacity in these countries scales down both energy productivity and energy intensity (rebound effect): lower energy intensity gains are taken back by lower energy productivity. As it is measured by the availability and quality of roads and railway networks and air connectivity, better transport productive capacity may be motivating people to travel more. Thus, the net energy efficiency contribution may be achieved through a replacement of personal and energy-intensive transportation modes with public transports and energy-saving alternates. Similarly, energy labels may guide consumers towards more energysaving transport modes and transport equipment. As it is not that easy to change peoples' energy consumption behaviors especially in energy-rich countries, stringent energy standards on personal cars, transportations, and logistics are applicable policy actions. More specifically, the ownership of more personal cars may be restricted by strict regulations and high taxes. Again, the rules and tolls of roads may be regulated in favor of carpooling and public transportation.

Higher ICT capacity encourages energy productivity performance but it is also coupled to energy intensity for this sub-sample. The ICT rebound effect reveals the need for the conveyance of the fact that energy sources are not limitless to resource-abundant societies. Environmental awareness programs, as well as binding energy standards enforced by taxes or fines, may work well in increasing the societal commitment to energy efficiency. The resource-dependent countries' group is behind the upper-middle-income and highincome groups in terms of institutional capacity. We found institutional capacity as a driver of energy efficiency, significantly from the energy productivity side. Thus, stronger institutional framework features such as regulatory quality, anti-corruption, good governance, and freedom should be improved in resource-dependent countries. For this subsample, one can expect that private sectors are concentrating on extractive sectors and paying less attention to energy productivity. However, we found that these countries might get energy productivity benefits from the development of the private sector. Thus, policy-makers in these countries should support the private enterprises, especially in non-resource sectors, by easing the procedures in opening to international trade, starting and doing business, accessing finance, etc. The structural change obstructs energy productivity for this group. This implies that the structural change, in these 
countries, has not yet developed so as to increase overall energy efficiency. Thus, customized energy efficiency initiatives need to be accompanied by additional green industrial development policies to develop the energy-efficient private sector, particularly in non-resource industries. Overall, the mixed findings open the ground to future research on the energy consumption behaviors of enterprises and individuals in resource-rich economies.

(v) World sample: Energy efficiency, environmental quality, and resource conservation are interconnected and among the common global tasks. There is an unbalanced development of energy efficiency across the globe. Much more is needed to close the existing performance gap between high and low performers. Therefore, this study also aimed to provide evidence and policy implications from a broader perspective at the world level.

The statistically insignificant impact of per capita income has an economically significant implication that the neutral effect may be improved towards disconnecting economic growth from excessive use of energy sources. The global findings showed some driving and inhibiting forces of socioeconomic factors to how this decoupling can be achieved. The development of human capital has a dual contribution (high energy productivity and low energy intensity) to energy efficiency. Such components of human capital as quality education, better health conditions, gender equality, and higher investment in research and development are among the key pillars in international sustainable development programs. In these initiatives, human capital development projects may help lagger countries to access the components of human capital. Especially, local programs in low-income countries should be supported both technically and financially to invest more in human capital.

Notably, since the early 2000s, international production, trade, and investments are increasingly managed by global value chains, in which many countries contribute to the different stages of the production process of a great number of products. Global value chains also need well-operating global supply chains facilitated by good logistics and quality transports. Knowing this, many countries have been investing in the improvement of transport and logistics capacities. However, this trend may impair the energy efficiency trajectory of the world as we found the improved transport capacity associated with lower energy productivity and higher energy intensity. The latter effect is easier to explain that better transport motivates people to travel and carry their needs more often between destinations. Transport inherently scales up the energy intensity as the increased mobility of people and products uses more energy. Therefore, the policy suggestion is simple that countries need to transform their transports and logistics into more energy-efficient modes (green transport ad green logistics) enforced by energy efficiency standards. However, the controversial negative nexus between transport and energy productivity requires an indepth insight that better transport across the world brings about new demand for goods and services, which might be supplied at a cost of increasing energy use. Likewise, improved transport enables to carry new energy sources between destinations both within and between countries. This may lead to an increase in the relative share of energy in production. Increased world capacity in transport has made it easier and cheaper to carry energy sources and products. From the international trade and investment perspective, improved global transport capacity may lead to agglomeration of energy-inefficient production in some resource-abundant developing countries/regions where energy standards are lenient. This implies a need to introduce new energy regulations enforced globally in the explorations of energy sources and in the use of energy for production. In order to hinder the possible energy inefficiency competition in international trade, these regulations should be also reflected in the trade schemes of countries and controlled how energy efficiently the traded goods are produced.

It is long argued that ICT advancement and digital transformation improve energy efficiency at the world level. We confirmed this argument only from the energy productivity side, indicating that the prevalence of ICT-enabled technologies and services may foster decoupling production from energy use. However, the increased ICT capacity also causes higher energy intensity which indicates the increasing energy burden of ICT development. This rebound effect infers that the production of modern digital ICT technologies entails supports to replace energy-intensive ones. Since this evidence implies that the world has not yet achieved energy efficiency gains from ICT expansion, introducing 'energyefficient ICT' and 'ICT for energy efficiency' initiatives is one of the potential solutions to curb energy consumption from ICT use. The complexity of the ICT-energy efficiency nexus and the motivational drivers of behavioral changes towards the use of more energy-efficient ICT components leave a research domain for future studies. Our results also showed that increased capacity in institutions and structural change stimulated energy productivity globally. These pieces of evidence argue that global energy initiatives and environmental studies require the incorporation of economic structure and institutional quality into energy policies. Therefore, the worldwide spread of political stability, fighting corruption and terrorism, and improving freedom will provide some channels through which world production will be more energy-productive. Likewise, an overall global movement of energy resources from low to high productive economic activities will improve overall global energy productivity. However, there are some political challenges 
setting barriers to the productivity-oriented global allocation of energy sources. Energy organizations of resourcerich countries, as well as national energy institutions, should adopt social responsibility and transparency merits. Governments, institutional behaviors, and energy policies in these countries may be observed and assessed by international corporations authorized with binding sanctions against the exploitation of energy sources. Emission-mitigation efforts of international initiatives such as the Kyoto Protocol may pay more attention to energy efficiency directions in the participating countries.

Overall, our study calls into question the use of a onedata indicator of energy efficiency. We suggest that energy policies at all global, regional, and country levels should be addressed for energy productivity and energy efficiency separately. It is certain that the one-size-fits-all solution to global energy inefficiency concerns will fail due to the presence of strong country heterogeneity. Since the energysaving practices of individuals may be affected by their expectations for financial savings, energy efficiency strategies should enable the comparisons of future monetary gains with the present cost of energy-saving practices. In the context of the combination of environmental concerns and financial motivation, supplying cheaper renewable energy plays a central role in meeting the rising global demand for primary energy resources. For the behavioral change in societies, in addition to companies' training programs, educational institutions should also include energy efficiency subjects in their curriculums at all levels to strengthen the public awareness of the alarming climate impacts of the global depletion of finite energy sources. Future studies providing global evidence of the adverse effects on health, climate change, environmental pollution, and natural disasters of the exploitation of energy sources will help in the societal understanding of the importance of energy efficiency.

\section{Limitations and future research}

This study has some conceptual and analytical limitations, which should be addressed in future research. Conceptually, we did not distinguish any kinds of energy as we dealt with the overall energy efficiency. Future studies may make distinctions, for example between renewable and non-renewable (fossil and non-fossil) energy or electric and non-electric energy. Relying on the existing evidence and the persistently largest share of emissions-intensive fossil fuels in the total primary energy supply, we sometimes associate energy inefficiency with environmental deterioration without knowing the actual relationships in our case. It should be noted that the energy intensity concept we gauged as per capita energy supply embodies some geographic characteristics such as climate and location, and demographic factors such as population and house/family size. Future micro-level studies may control for specific demographics of individuals, employees, and enterprises within countries. We focused on the resource depletion impact of energy intensity and thereby measured it in physical amounts as oil equivalent. Further studies may also use monetary metrics to capture the price and cost impacts.

The energy efficiency performance of countries may change across different sectors such as manufacturing, transportations, and construction industries, as well as some service sectors. Again, there are highly likely heterogeneities in countries' energy efficiency policies. Although our resulting linear models fitted well the data of all samples and passed some diagnostic tests, there likely exist some nonlinear dynamic relationships caused by structural breaks in some countries' series. Moreover, the estimated relationships may change from the short-run to the long-run. Even though we strictly regrouped countries by income level and resource dependence, presupposing that these categories are purely homogeneous in terms of energy efficiency and socio-economic productive capacities is far from the truth. The analytical framework of this study does not cover these effects. Thus, the generalization of the findings and relevant policy implications to individual countries needs some caution. These shortcomings provide niches for future studies which adopt sectoral approaches and employ varied dynamic analysis methods on individual countries and different country groups. These considerations will better explain feedback loops and rebound effects between energy productivity (production-side), energy intensity (consumption-side), and socio-economic indicators.

Acknowledgements The authors are grateful to the journal's editor and four anonymous reviewers whose extensive comments and helpful recommendations improved the study. The authors also appreciate the open-access availability of the valuable databases of OECD, UNCTAD, and World Bank.

Author contribution MD designed the research method, collected the data, and performed the regression analysis and causality test. OD reviewed the literature and applied the analysis of variance. Both authors equally contributed to the discussion of the findings and writing of the paper.

Data availability The datasets generated and/or analyzed during the current study are available in the [Google-Drive] repository, [https:// drive.google.com/file/d/1C2bK7diOTDbIFqGuIblYX5DpoRviY5oE/ view? $\mathrm{usp}=$ sharing]. Unreported statistics/results are also available from the authors on reasonable request.

\section{Declarations}

Ethics approval and consent to participate Not applicable. This study does not report on or involve the use of any animal or human data or tissue. It used open access data which is not involving human participants, human data, or human tissue. 
Consent for publication Not applicable. This study does not contain data from any individual person.

Competing interests The authors declare no competing interests.

\section{References}

Ackah I, Kizys R (2015) Green growth in oil producing African countries: a panel data analysis of renewable energy demand. Renew Sust Energ Rev 50:1157-1166. https://doi.org/10.1016/j.rser. 2015.05.030

Adetutu MO, Glass AJ, Weyman-Jones TG (2016) Economy-wide estimates of rebound effects: evidence from panel data. Energy J 37(3):251-269. https://doi.org/10.5547/01956574.37.3.made

Akhbari R, Nejati M (2019) The effect of corruption on carbon emissions in developed and developing countries: empirical investigation of a claim. Heliyon 5(9):e02516. https://doi.org/10.1016/j. heliyon.2019.e02516

Alarenan S, Gasim AA, Hunt LC, Muhsen AR (2019) Measuring underlying energy efficiency in the GCC countries using a newly constructed dataset. Energy Transit 3:31-44. https://doi.org/10. 1007/s41825-019-00012-y

Aldieri L, Makkonen T, Vinci CP (2020) Environmental knowledge spillovers and productivity: a patent analysis for large international firms in the energy, water and land resources fields. Resour Policy 69:101877. https://doi.org/10.1016/j.resourpol. 2020.101877

Altinoz B, Dogan E (2021) How renewable energy consumption and natural resource abundance impact environmental degradation? New findings and policy implications from quantile approach. Energy Sources Part B 16(4):345-356. https://doi.org/10.1080/ 15567249.2021 .1885527

Ambec S, Lanoie P (2008) Does it pay to be green? A systematic overview. Acad Manag Perspect 22(4):45-62. https://doi.org/10. 5465/amp.2008.35590353

Atalla T, Bean P (2017) Determinants of energy productivity in 39 countries: an empirical investigation. Energy Econ 62:217-229. https://doi.org/10.1016/j.eneco.2016.12.003

Azam M, Liu L, Ahmad N (2021) Impact of institutional quality on environment and energy consumption: evidence from developing world. Environ Dev Sustain 23:1646-1667. https://doi.org/10. 1007/s10668-020-00644-x

Baloch ZA, Tan Q, Iqbal N, Mohsin M, Abbas Q, Iqbal W, Chaudhry IS (2020) Trilemma assessment of energy intensity, efficiency, and environmental index: evidence from BRICS countries. Environ Sci Pollut Res 27:34337-34347. https://doi.org/10.1007/ s11356-020-09578-3

Baloch ZA, Tan Q, Kamran HW, Nawaz MA, Albashar G, Hameed J (2021) A multi-perspective assessment approach of renewable energy production: policy perspective analysis. Environ Dev Sustain. https://doi.org/10.1007/s10668-021-01524-8

Baltagi BH (2013) Econometric analysis of panel data, 5th edn. Wiley, Chichester, West Sussex

Baltagi BH, Pesaran MH (2007) Heterogeneity and cross section dependence in panel data models: theory and applications introduction. J Appl Econ 22:229-232. https://doi.org/10.1002/jae. 955

Baltagi BH, Feng Q, Kao C (2012) Lagrange Multiplier test for cross-sectional dependence in a fixed effects panel data model. J Econom 170(1):164-177. https://doi.org/10.1016/j.jeconom. 2012.04.004
Bell A, Fairbrother M, Jones K (2019) Fixed and random effects models: making an informed choice. Qual Quant 53:1051-1074. https://doi.org/10.1007/s11135-018-0802-X

Blanco L, Grier R (2012) Natural resource dependence and the accumulation of physical and human capital in Latin America. Resour Policy 37(3):281-295. https://doi.org/10.1016/j.resourpol.2012. 01.005

Breusch T, Pagan A (1980) The Lagrange Multiplier test and its application to model specification in econometrics. Rev Econ Stud 47(1):239-253. https://doi.org/10.2307/2297111

Brinkerink J, Chegut A, Letterie W (2019) Energy performance and capital expenditures in manufacturing industries. Energy Effic 12:2011-2038. https://doi.org/10.1007/s12053-019-09779-x

Brockway PE, Sorrell S, Semieniuk G, Heun MK, Court V (2021) Energy efficiency and economy-wide rebound effects: a review of the evidence and its implications. Renew Sustain Energy Rev 141:110781. https://doi.org/10.1016/j.rser.2021.110781

Castiglione C, Infante D, Smirnova J (2015) Environment and economic growth: is the rule of law the go-between? The case of high-income countries. Energy Sustain Soc 5(26). https://doi. org/10.1186/s13705-015-0054-8

Chang SC (2015) Effects of financial developments and income on energy consumption. Int Rev Econ Finance 35:28-44. https:// doi.org/10.1016/j.iref.2014.08.011

Cornillie J, Fankhauser S (2004) The energy intensity of transition countries. Energy Econ 26(3):283-295. https://doi.org/10.1016/j. eneco.2004.04.015

Deichmann U, Reuter A, Vollmer S, Zhang F (2018) Relationship between energy intensity and economic growth: new evidence from a multi-country multi-sector data set. WB Policy Research WP, 8322. https://openknowledge.worldbank.org/handle/10986/ 29288. Accessed 19 Aug 2021

Dinno A (2015) Nonparametric pairwise multiple comparisons in independent groups using Dunn's test. Stata J 15(1):292-300. https:// doi.org/10.1177/1536867X1501500117

Dumitrescu EI, Hurlin C (2012) Testing for granger noncausality in heterogeneous panels. Econ Model 29(4):1450-1460. https://doi. org/10.1016/j.econmod.2012.02.014

Dunlop T (2019) Mind the gap: a social sciences review of energy efficiency. Energy Res Soc Sci 56:101216. https://doi.org/10. 1016/j.erss.2019.05.026

Efobi U, Belmondo T, Orkoh E, Atata SN, Akinyemi O, Beecroft I (2019) Environmental pollution policy of small businesses in Nigeria and Ghana: extent and impact. Environ Sci Pollut Res 26:2882-2897. https://doi.org/10.1007/s11356-018-3817-x

El Menyari Y (2021) The effects of international tourism, electricity consumption, and economic growth on $\mathrm{CO} 2$ emissions in North Africa. Environ Sci Pollut Res 28:44028-44038. https://doi.org/ 10.1007/s11356-021-13818-5

Erum N, Hussain S (2019) Corruption, natural resources and economic growth: evidence from OIC countries. Resour Policy 63:101429. https://doi.org/10.1016/j.resourpol.2019.101429

Esseghir A, Khouni LH (2014) Economic growth, energy consumption and sustainable development: the case of the Union for the Mediterranean countries. Energy 71:218-225. https://doi.org/10. 1016/j.energy.2014.04.050

Figueroa M, Lah O, Fulton LM, McKinnon A, Tiwari G (2014) Energy for transport. Annu Rev Environ Resour 39:295-325. https://doi. org/10.1146/annurev-environ-031913-100450

Galvin R (2015) The ICT/electronics question: structural change and the rebound effect. Ecol Econ 120:23-31. https://doi.org/10. 1016/j.ecolecon.2015.08.020

Georgatzi VV, Stamboulis Y, Vetsikas A (2020) Examining the determinants of $\mathrm{CO}_{2}$ emissions caused by the transport sector: 
empirical evidence from 12 European countries. Econ Anal Policy 65:11-20. https://doi.org/10.1016/j.eap.2019.11.003

Goh T, Ang BW (2020) Four reasons why there is so much confusion about energy efficiency. Energy Policy 146:111832. https://doi. org/10.1016/j.enpol.2020.111832

Goldemberg J (1996) A note on the energy intensity of developing countries. Energy Policy 24(8):759-761. https://doi.org/10. 1016/0301-4215(96)00045-6

Greene WH (2012) Econometric analysis, 7th edn. Pearson, Harlow, Essex

Hailu D, Kipgen C (2017) The Extractives Dependence Index (EDI). Resour Policy 51:251-264. https://doi.org/10.1016/j.resourpol. 2017.01.004

Hang L, Tu M (2007) The impacts of energy prices on energy intensity: evidence from China. Energy Policy 35(5):2978-2988. https://doi.org/10.1016/j.enpol.2006.10.022

Hausman JA (1978) Specification tests in econometrics. Econometrica 46(6):1251-1272. https://doi.org/10.2307/1913827

Havranek T, Horvath R, Zeynalov A (2016) Natural resources and economic growth: a meta-analysis. World Dev 88:134-151. https://doi.org/10.1016/j.worlddev.2016.07.016

He Y, Lin B (2019) Investigating environmental Kuznets curve from an energy intensity perspective: empirical evidence from China. J Clean Prod 234:1013-1022. https://doi.org/10.1016/j. jclepro.2019.06.121

Hecke TV (2012) Power study of ANOVA versus Kruskal-Wallis test. J Stat Manag Syst 15(2-3):241-247. https://doi.org/10. $1080 / 09720510.2012 .10701623$

Hoffman AJ, Jennings PD (2015) Institutional theory and the natural environment: research in (and on) the anthropocene. Organ Environ 28(1):8-31. https://doi.org/10.1177/1086026615 575331

Honda Y (1985) Testing the error components model with non-normal disturbances. Rev Econ Stud 52(4):681-690. https://doi. org/10.2307/2297739

Honda Y (1991) A standardized test for the error components model with the two-way layout. Econ Lett 37(2):125-128. https://doi. org/10.1016/0165-1765(91)90119-6

IEA (2010) Transport energy efficiency implementation of IEA recommendations since 2009 and next steps. OECD/IEA, Paris

IEA (2019) World Energy Outlook 2019. IEA, Paris

IEA (2020) World Energy Outlook 2020. IEA, Paris

IMF (2012) Macroeconomic policy framework for resource-rich developing countries. IMF, Washington, DC

Irandoust M (2019) On the causality between energy efficiency and technological innovations: limitations and implications. Int J Green Energy 16(15):1665-1675. https://doi.org/10.1080/ 15435075.2019 .1681430

Irfan M (2021) Low-carbon energy strategies and economic growth in developed and developing economies: the case of energy efficiency and energy diversity. Environ Sci Pollut Res. https:// doi.org/10.1007/s11356-021-14070-7

Lange S, Pohl J, Santarius T (2020) Digitalization and energy consumption. Does ICT reduce energy demand? Ecol Econ 176:106760. https://doi.org/10.1016/j.ecolecon.2020.106760

Le HP, Ozturk I (2020) The impacts of globalization, financial development, government expenditures, and institutional quality on $\mathrm{CO}_{2}$ emissions in the presence of environmental Kuznets curve. Environ Sci Pollut Res 27:22680-22697. https://doi.org/ 10.1007/s11356-020-08812-2

Li Y (2019) Prediction of energy consumption: variable regression or time series? A case in China. Energy Sci Eng 7:2510-2518. https://doi.org/10.1002/ese3.439

Li K, Hu E, Xu C, Musah M, Kong Y, Mensah IA, Zu J, Jiang W, Su Y (2021a) A heterogeneous analysis of the nexus between energy consumption, economic growth and carbon emissions: evidence from the Group of Twenty (G20) countries. Energy Explor Exploit 39(3):815-837. https://doi.org/10.1177/01445 98720980198

Li X, Sohail S, Majeed MT, Ahmad W (2021b) Green logistics, economic growth, and environmental quality: evidence from one belt and road initiative economies. Environ Sci Pollut Res. https://doi. org/10.1007/s11356-021-12839-4

Liddle B (2014) Impact of population, age structure, and urbanization on carbon emissions/energy consumption: evidence from macrolevel, cross-country analyses. Popul Environ 35:286-304. https:// doi.org/10.1007/s11111-013-0198-4

Liu J, Yuan C, Hafeez M, Yuan Q (2018) The relationship between environment and logistics performance: evidence from Asian countries. J Clean Prod 204:282-291. https://doi.org/10.1016/j. jclepro.2018.08.310

Lv T, Wu X (2019) Using panel data to evaluate the factors affecting transport energy consumption in China's three regions. Int J Environ Res Public Health 16(4):555. https://doi.org/10.3390/ ijerph16040555

Martinez CIP (2016) Estimating and analyzing energy efficiency in German and Colombian manufacturing industries using DEA and data panel analysis. Part II: Non-energy intensive sectors. Energy Sources Part B 11(1):1-10. https://doi.org/10.1080/ 15567249.2010 .551823

Mensah IA, Sun M, Omari-Sasu AY, Gao C, Obobisa ES, Osinubi TT (2021) Potential economic indicators and environmental quality in African economies: new insight from cross-sectional autoregressive distributed lag approach. Environ Sci Pollut Res. https:// doi.org/10.1007/s11356-021-14598-8

Midway S, Robertson M, Flinn S, Kaller M (2020) Comparing multiple comparisons: practical guidance for choosing the best multiple comparisons test. PeerJ 8:e10387. https://doi.org/10.7717/peerj. 10387

Montalbano P, Nenci S (2019) Energy efficiency, productivity and exporting: firm-level evidence in Latin America. Energy Econ 79:97-110. https://doi.org/10.1016/j.eneco.2018.03.033

Murshed M (2020) An empirical analysis of the non-linear impacts of ICT-trade openness on renewable energy transition, energy efficiency, clean cooking fuel access and environmental sustainability in South Asia. Environ Sci Pollut Res 27:36254-36281. https://doi.org/10.1007/s11356-020-09497-3

Nathaniel SP, Yalçiner K, Bekun FV (2021) Assessing the environmental sustainability corridor: linking natural resources, renewable energy, human capital, and ecological footprint in BRICS. Resour Policy 70:101924. https://doi.org/10.1016/j.resourpol. 2020.101924

Nepal R, Jamasb T, Tisdell CA (2014) Market-related reforms and increased energy efficiency in transition countries: empirical evidence. Appl Econ 46(33):4125-4136. https://doi.org/10.1080/ 00036846.2014 .952894

Neumayer E (2002) Do democracies exhibit stronger international environmental commitment? A cross-country analysis. J Peace Res 39(2):139-164. https://doi.org/10.1177/0022343302039002001

Nyangon J, Byrne J (2021) Spatial energy efficiency patterns in New York and implications for energy demand and the rebound effect. Energy Sources Part B 16(2):135-161. https://doi.org/10.1080/ 15567249.2020 .1868619

OECD (2017) Green growth indicators 2017. OECD, Paris. https://doi. org/10.1787/22229523. (Accessed 4 Feb 2021)

OECD (2011) OECD green growth studies: Energy. https://www.oecd. org/greengrowth/greening-energy/49157219.pdf. Accessed 19 Aug 2021

OECD (2021) Environment database. https://stats.oecd.org/. Accessed 4 Feb 2021 
Ostertagová E, Ostertag O, Kováč J (2014) Methodology and application of the Kruskal-Wallis test. Appl Mech Mater 611:115-120. https://doi.org/10.4028/www.scientific.net/amm.611.115

Ozturk I (2010) A literature survey on energy-growth nexus. Energy Policy 38(1):340-349. https://doi.org/10.1016/j.enpol.2009.09. 024

Ozturk I, Al-Mulali U, Solarin SA (2019) The control of corruption and energy efficiency relationship: an empirical note. Environ Sci Pollut Res 26:17277-17283. https://doi.org/10.1007/ s11356-019-05016-1

Pata UK, Aydin M, Haouas I (2021) Are natural resources abundance and human development a solution for environmental pressure? Evidence from top ten countries with the largest ecological footprint. Resour Policy 70:101923. https://doi.org/10.1016/j.resou rpol.2020.101923

Pesaran MH (2007) A simple panel unit root test in the presence of cross-section dependence. J Appl Econom 22:265-312. https:// doi.org/10.1002/jae.951

Pesaran MH (2021) General diagnostic tests for cross-sectional dependence in panels. Empir Econ 60:13-50. https://doi.org/10.1007/ s00181-020-01875-7

Pohlert T (2014) The pairwise multiple comparison of mean ranks package (PMCMR): R package. http://CRAN.R-project.org/ package $=$ PMCMR. Accessed 20 Aug 2021

Porter ME, Van der Linde C (1995) Toward a new conception of the environment-competitiveness relationship. J Econ Perspect 9(4):97-118. https://doi.org/10.1257/jep.9.4.97

Rieger A (2019) Doing business and increasing emissions? An exploratory analysis of the impact of business regulation on $\mathrm{CO}_{2}$ emissions. Hum Ecol Rev 25(1):69-86. https://doi.org/10.22459/ HER.25.01.2019.04

Rohdin P, Thollander P, Solding P (2007) Barriers to and drivers for energy efficiency in the Swedish foundry industry. Energy Policy 35(1):672-677. https://doi.org/10.1016/j.enpol.2006.01.010

Ryan N (2018) Energy productivity and energy demand: experimental evidence from Indian manufacturing plants. NBER WPs 24619. https://doi.org/10.3386/w24619

Sadorsky P (2012) Information communication technology and electricity consumption in emerging economies. Energy Policy 48:130-136. https://doi.org/10.1016/j.enpol.2012.04.064

Sahoo M, Saini S, Villanthenkodath MA (2021) Determinants of material footprint in BRICS countries: an empirical analysis. Environ Sci Pollut Res 28:37689-704. https://doi.org/10.1007/ s11356-021-13309-7

Salahuddin M, Alam K (2016) Information and communication technology, electricity consumption and economic growth in OECD countries: a panel data analysis. Int J Electr Power Energy Syst 76:185-193. https://doi.org/10.1016/j.ijepes.2015.11.005

Schulte P, Welsch H, Rexhäuser S (2016) ICT and the demand for energy: evidence from OECD countries. Environ Resour Econ 63:119-146. https://doi.org/10.1007/s10640-014-9844-2

Shahbaz M, Destek MA, Okumus I, Sinha A (2019) An empirical note on comparison between resource abundance and resource dependence in resource abundant countries. Resour Policy 60:47-55. https://doi.org/10.1016/j.resourpol.2018.12.002

Shrivastava P (1995) The role of corporations in achieving ecological sustainability. Acad Manag Rev 20(4):936-960. https://doi.org/ 10.5465/amr.1995.9512280026

Sineviciene L, Sotnyk I, Kubatko O (2017) Determinants of energy efficiency and energy consumption of Eastern Europe post-communist economies. Energy Environ 28(8):870-884. https://doi. org/10.1177/0958305X17734386

Soppelsa ME, Lozano-Gracia N, Xu LC (2021) The effects of pollution and business environment on firm productivity in Africa.
Int Reg Sci Rev 44(2):203-228. https://doi.org/10.1177/01600 17620931572

Soytas U, Sari R (2003) Energy consumption and GDP: causality relationship in G-7 countries and emerging markets. Energy Econ 25(1):33-37. https://doi.org/10.1016/S0140-9883(02)00009-9

Steinberger JK, Krausmann F (2011) Material and energy productivity. Environ Sci Technol 45(4):1169-1176. https://doi.org/10.1021/ es1028537

Sun H, Edziah BK, Sun C, Kporsu AK (2019) Institutional quality, green innovation and energy efficiency. Energy Policy 135:111002. https://doi.org/10.1016/j.enpol.2019.111002

Sutherland RJ (1994) Energy efficiency or the efficient use of energy resources? Energy Sources 16(2):257-268. https://doi.org/10. 1080/00908319408909076

Takase K, Murota Y (2004) The impact of IT investment on energy: Japan and US comparison in 2010. Energy Policy 32(11):12911301. https://doi.org/10.1016/S0301-4215(03)00097-1

UNCTAD (2021b) UNCTAD productive capacities index: methodological approach and results. United Nations, Geneva

UNCTAD (2021a) UNCTADSTAT-Data Center. https://unctadstat. unctad.org/EN/. Accessed 11 Feb 2021

UNIDO (2011) Industrial energy efficiency in developing countries: a background note. UNIDO, Vienna

Usman A, Ozturk I, Hassan A, Zafar SM, Ullah S (2021) The effect of ICT on energy consumption and economic growth in South Asian economies: an empirical analysis. Telemat Inform 58:101537. https://doi.org/10.1016/j.tele.2020.101537

Van de Ven DJ, Fouquet R (2017) Historical energy price shocks and their changing effects on the economy. Energy Econ 62:204-216. https://doi.org/10.1016/j.eneco.2016.12.009

Velasco-Fernández R, Dunlop T, Giampietro M (2020) Fallacies of energy efficiency indicators: recognizing the complexity of the metabolic pattern of the economy. Energy Policy 137:111089. https://doi.org/10.1016/j.enpol.2019.111089

Ward H (2008) Liberal democracy and sustainability. Environ. Politics 17(3):386-409. https://doi.org/10.1080/09644010802055626

World Bank (2021) World Development Indicators. https://databank. worldbank.org/source/world-development-indicators. Accessed 18 Feb 2021

Yan Z, Shi R, Yang Z (2018) ICT development and sustainable energy consumption: a perspective of energy productivity. Sustainability 10:2568. https://doi.org/10.3390/su10072568

Yu L, Jia S, Shi Q (2009) Research on transportation-related emissions: current status and future directions. J Air Waste Manag Assoc 59(2):183-195. https://doi.org/10.3155/1047-3289.59.2.183

Zallé O (2019) Natural resources and economic growth in Africa: the role of institutional quality and human capital. Resour Policy 62:616-624. https://doi.org/10.1016/j.resourpol.2018.11.009

Zhang K, Batterman S (2013) Air pollution and health risks due to vehicle traffic. Sci Total Environ 15:307-316. https://doi.org/10. 1016/j.scitotenv.2013.01.074

Publisher's note Springer Nature remains neutral with regard to jurisdictional claims in published maps and institutional affiliations.

An earlier version of this study was presented at the International Conference on Economics, Energy, and Environment (ICEEE'2021) on 1 July 2021. 